\title{
APPLICATION OF THE PRINCIPLES OF GOVERNANCE IN THE REHABILITATION SECTOR: A FIELD STUDY AT THE MINISTRY OF EDUCATION IN THE SULTANATE OF OMAN

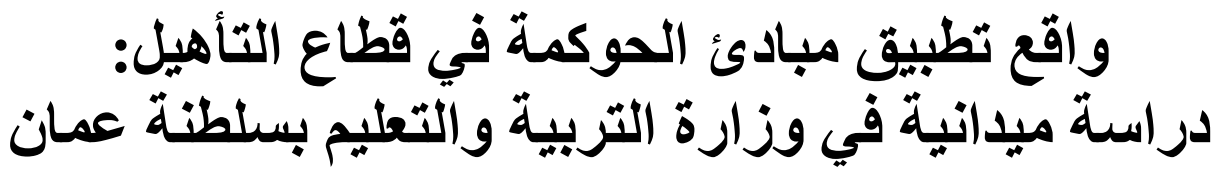

\author{
سلوى القصابي \\ Salwa Saif Ali Alqassabi ${ }^{1 *}$, Azam bin Othman² and Sueraya Che Haron ${ }^{3}$ \\ ${ }^{1} \mathrm{Ph}$.D. Candidate at Kulliyyah of Education, International Islamic University Malaysia (IIUM), \\ salwa7saif@gmail.com \\ ${ }^{2}$ Prof. Dr. at the Faculty of Education, International Islamic University Malaysia (IIUM), \\ azam othman@iium.edu.my \\ ${ }^{3}$ Senior lecture at Kulliyyah of Education, International Islamic University Malaysia (IIUM), \\ sueraya@iium.edu.my \\ ${ }^{*}$ Corresponding Author
}

\begin{abstract}
This quantitative study discussed the reality of applying the principles of governance in the rehabilitation sector in the Ministry of Education in the Sultanate of Oman. The problem has found in the results of the joint study between the Ministry and the Federation of New Zealand Educational Organizations (2017) in applying the principles of governance in Oman and promoting the improvement of the quality of education. The study team recommended that the Ministry of Education adapt and amend the current governance systems. Therefore, this study aimed at examining the reality of applying the principles of governance (partnership, transparency, justice, accountability) in the rehabilitation sector of the Ministry of Education, and diagnosing the challenges facing the Ministry of Education in applying the principles of governance. The study adopted the descriptive analytical method. The study population consisted of (2008) students. A stratified random sample was selected (322) individuals. A questionnaire was built at (49) paragraphs distributed in four dimensions of the governance. The study adopted the descriptive analysis. The findings showed: The general level of governance application came as a medium, as the principle of transparency came in the first place at an intermediate level, and secondly the principle of justice, then the principle of accountability, while the principle of partnership came in the last place.
\end{abstract}

Keywords: Governance, Rehabilitation Sector, Ministry of Education.

$$
\text { الملخص }
$$

ناقثت هذه الدراسة الكمية و اقع تطبيق مبادئ الحوكمة بقطاع التأهيل بوز ارة التربية والتعليم في

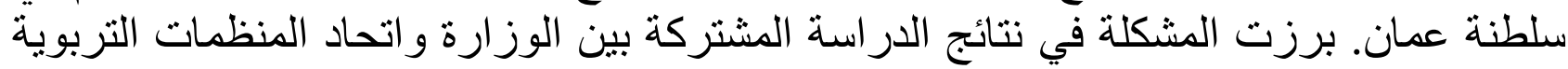
النيوزلندية (2017) في ضرورة تطبيق مبادئ الحوكمة بعناية في عمان، وتعزيز الارتقاء بجودة 
التعليم، وقد أوصى فريق الدراسة بأن تقوم وزارة التربية و التعليم بتكييف وتعديل نظم الحوكمة الحالية. لذا هدفت الدراسة الوقوف على واقع تطبيق التيق مبادئ الحوكمة (الثر اكة، الثفافية، العدالة،

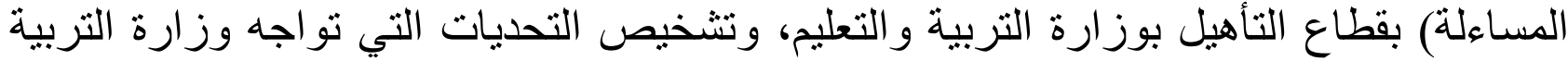

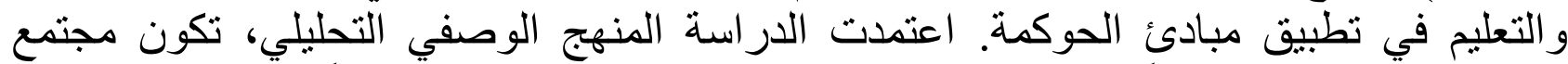

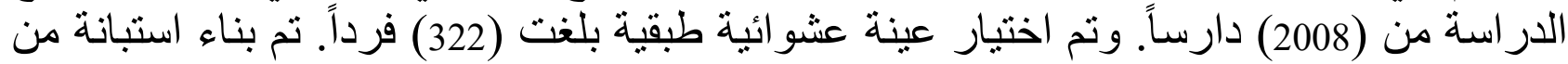

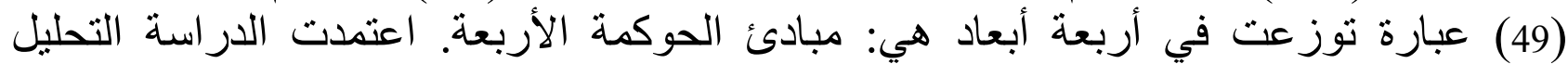

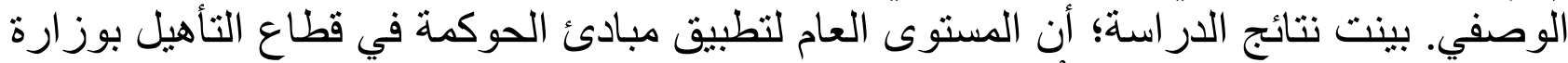

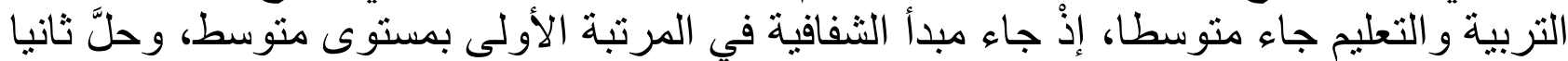

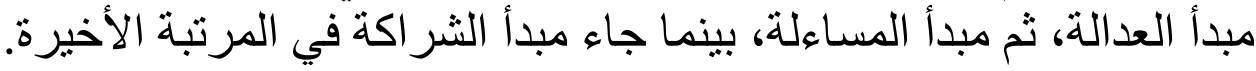
كلمات مفتاحية: الحوكمة، قطاع التأهيل، وزارة التربية.

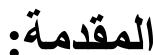

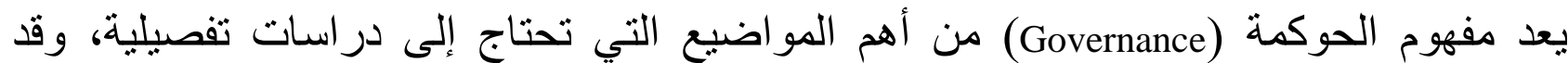

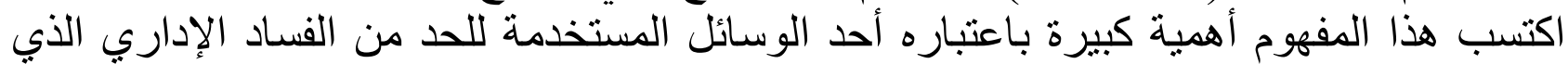

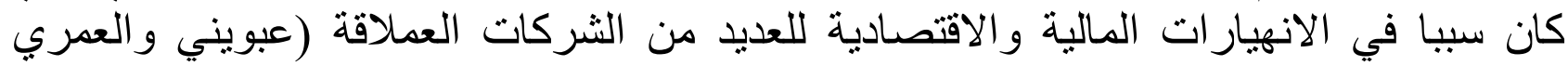

ويعتقد أن أصل مفهوم الحوكمة يوناني (kubemân)، استخدم في اللغة الفرنسية القديمة في القرن

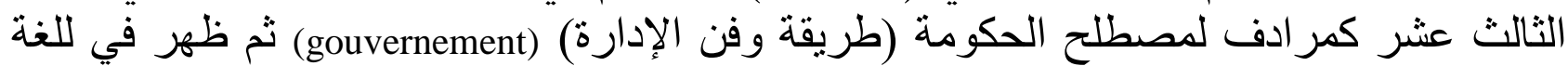
الإنجليزية (Governance) في القرن الر ابع عشر (Lamine.2008).

وقد عرفت منظمة التعاون الاقتصادي و التنمية (OECD) الحوكمة: "هي النظام الذي يوجه ويضبط الذاتيط

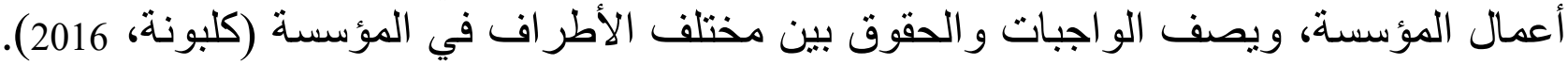
وتعتبر هذه المنظمة المؤسس الحقيقي لحوكمة الثركات، حين وضعت مجات مجموعة من المبادئ

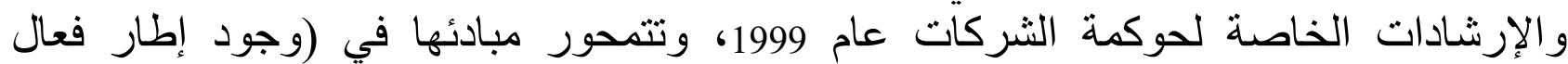

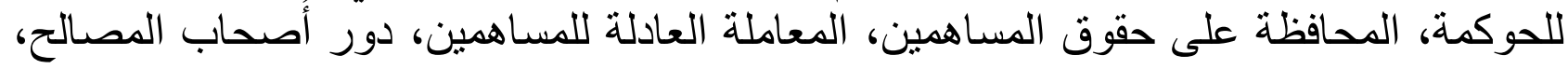
الإفصاح و الثفافية، ومسؤولية مجلس الإدارة) (الثويخ، 2013).

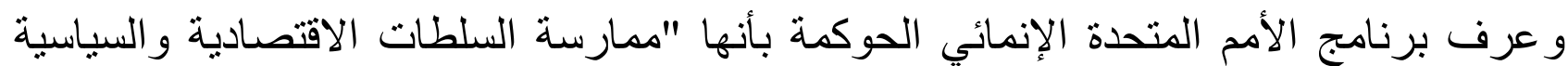

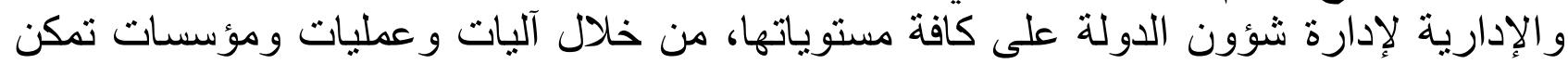

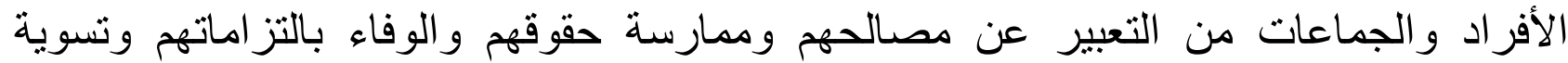

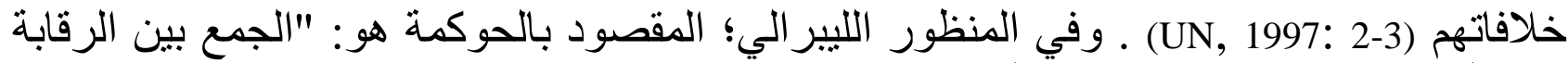

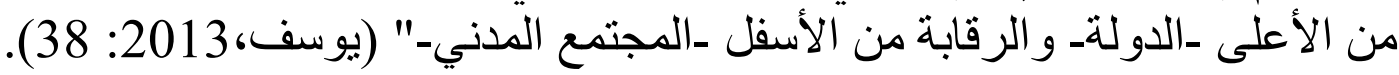

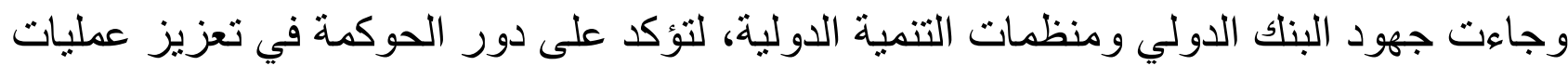

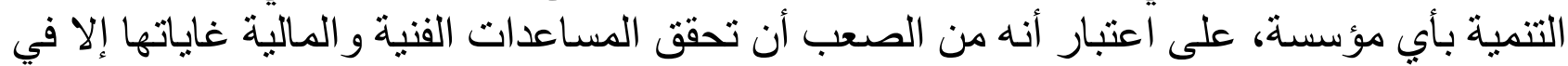

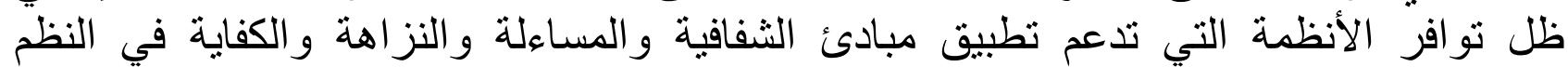


و المؤسسات (أبو قاعود، 2011). ويعتبر البنك الدولي من أبرز المؤسسات الدولية التي عملت

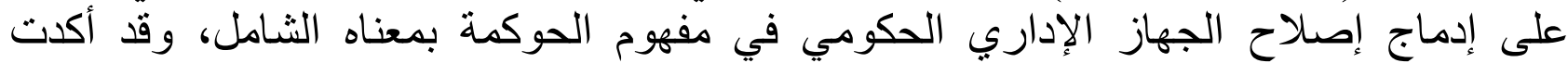

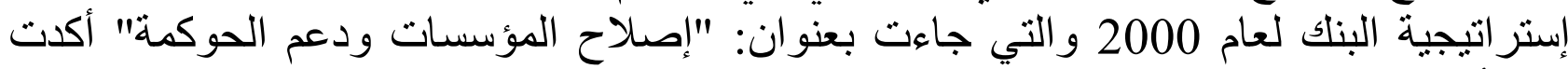
على أهمية الدفع بالحوكمة و التنمية السياسية وبناء القدر ات (2-2003: 1- World Bank, 2003).

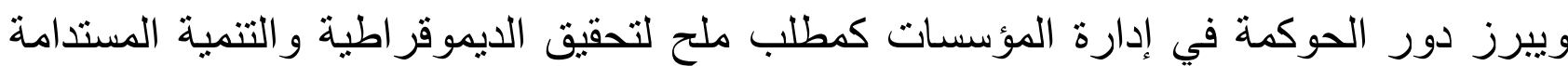

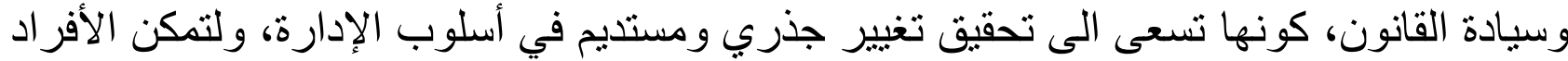

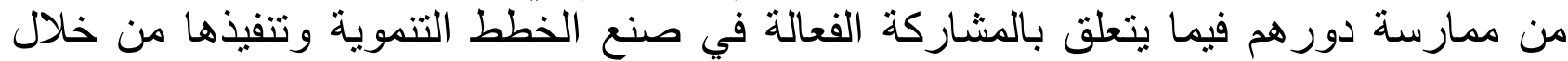

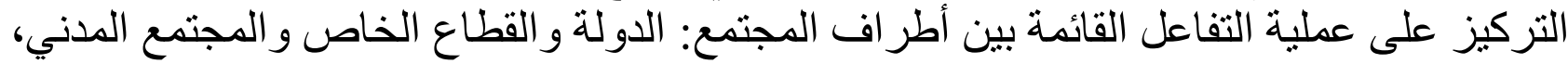

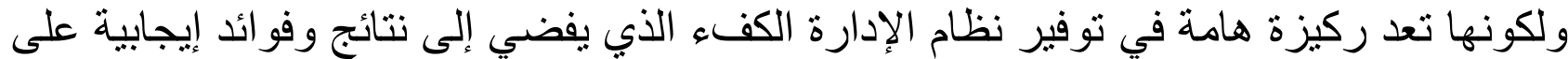

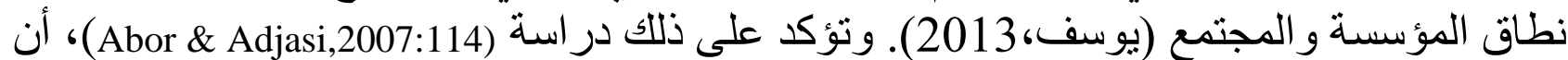

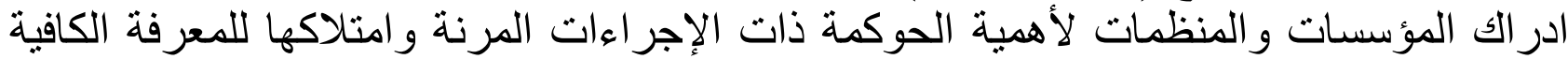

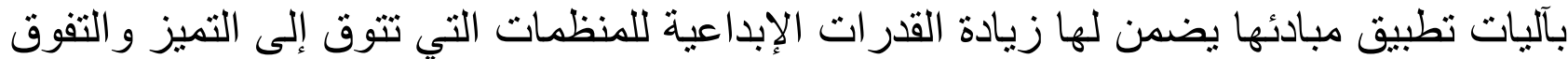

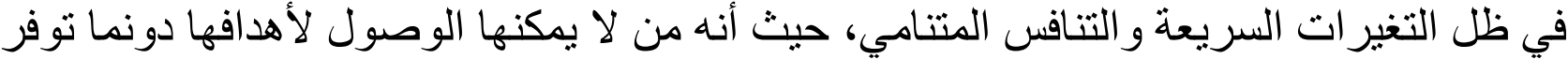

$$
\text { تبني لإجر اءات الحوكمة. }
$$

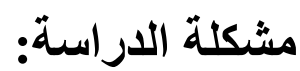

بناءً على تحليل خطط الإنماء المهني المختصة بحصر البرامج التأهيلية و التدريبية بوازرة التربية والتعليم اعتبار المن 2011 وحتى

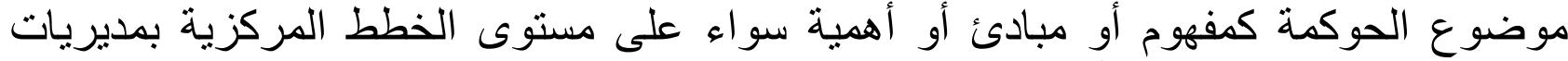

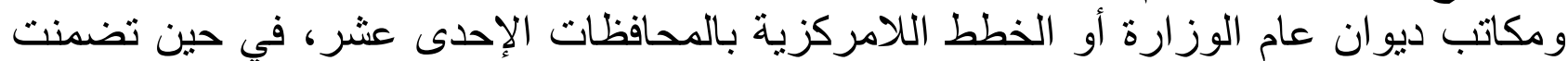

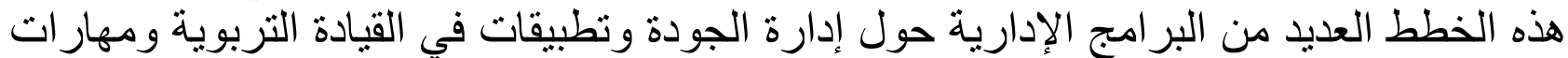

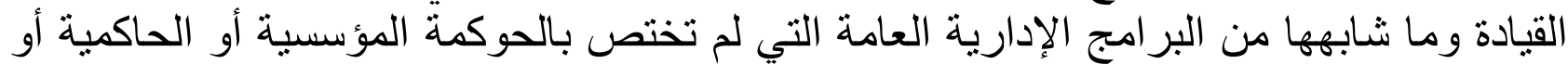

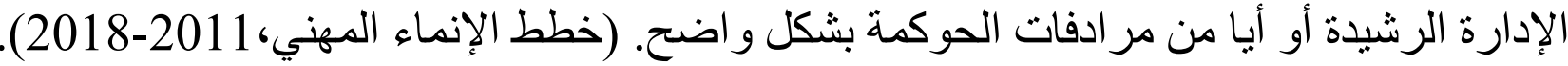

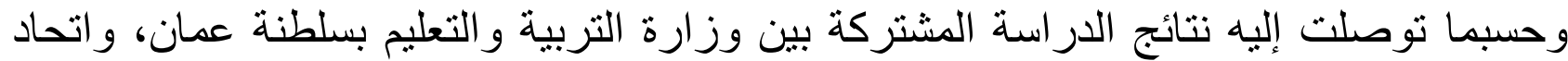

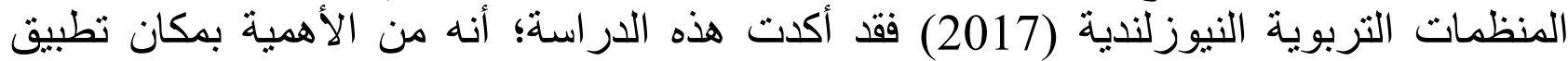

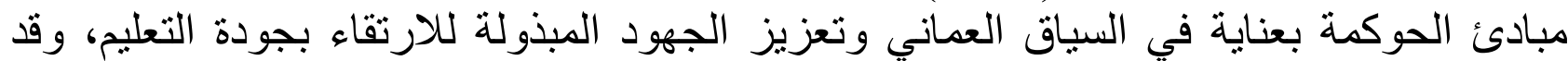

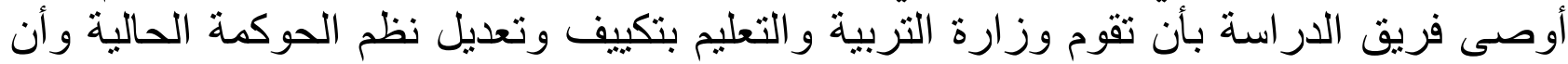

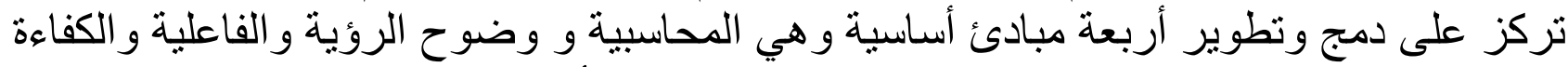

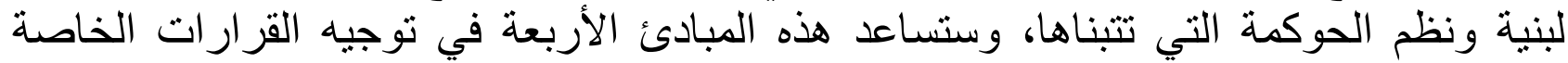
بالاستر اتيجيات و السياسات التربوية.

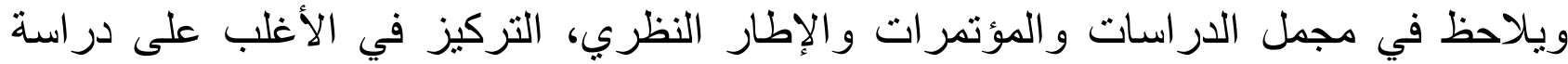

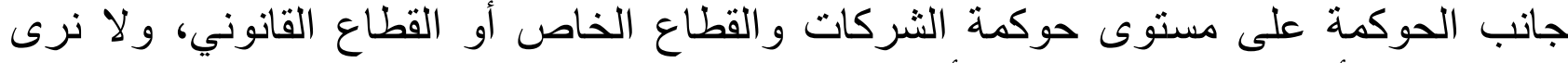

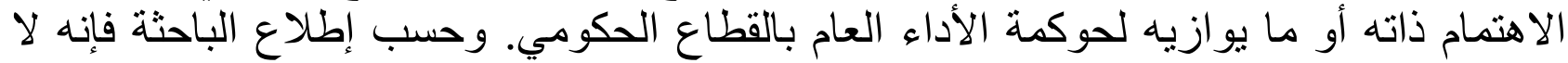

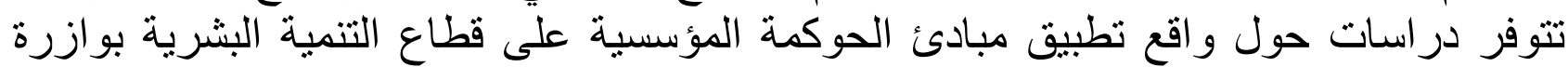
التربية والتعليم بسلطنة عمان حتى الآن، و إنما تركزت الترات معظم الدراسات على على المحاسبية المالية

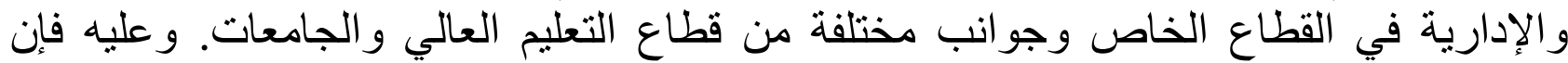
المؤسسات الحكومية عامة في سلطنة عمان ووزارة التربية والتعليم خاصَة بحاجة إلى أن أن تدرك 


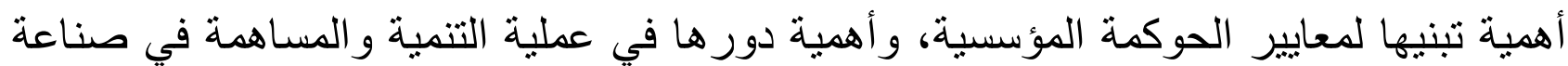

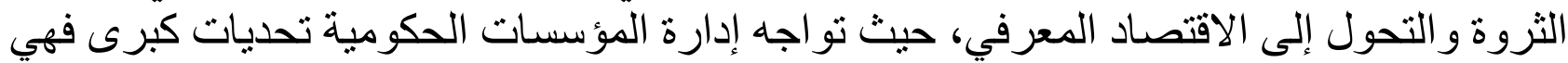

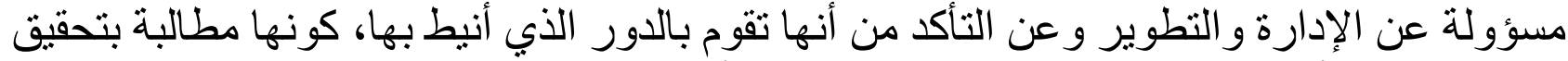

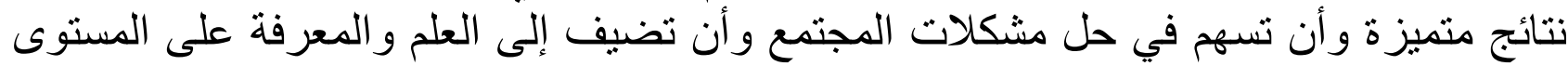

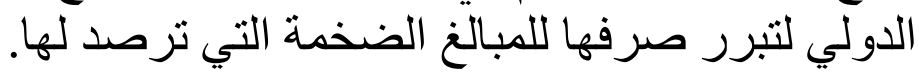

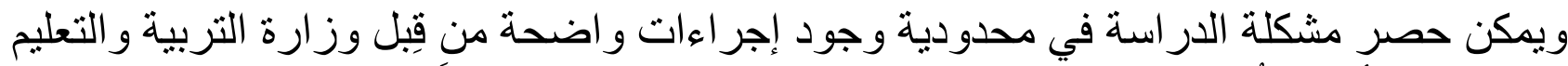

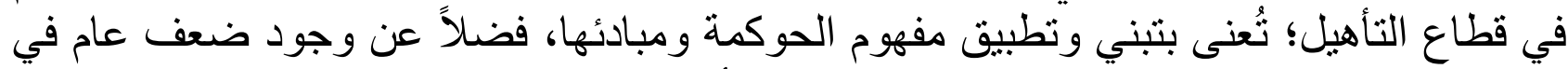

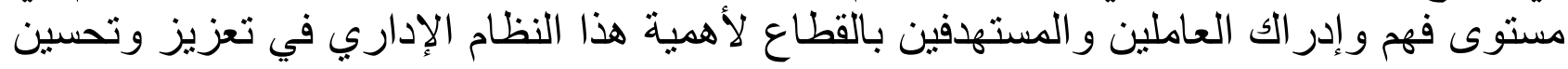

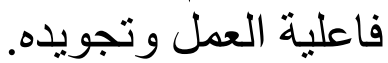

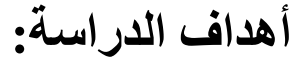

أ. الوقوف على واقع تطبيق مبادئ الحوكمة (الثر اكة، الثفافية، العدالة، المساءلة) بقطاع التأهيل

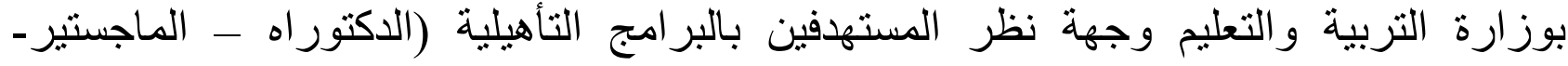

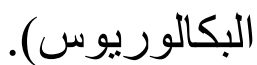

ب. تشخيص التحديات التي تواجه وزارة التربية و التعليم في تطبيق مبادئ الحوكمة (الثر اكة،

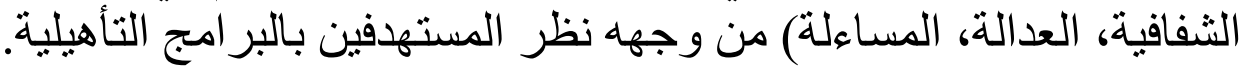

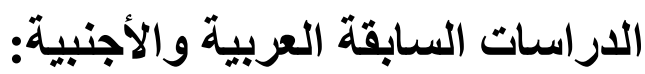

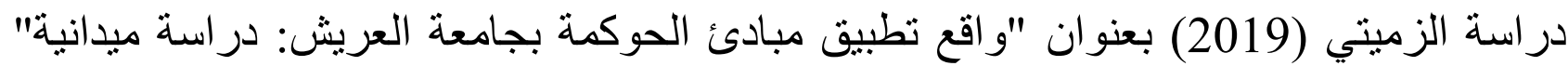

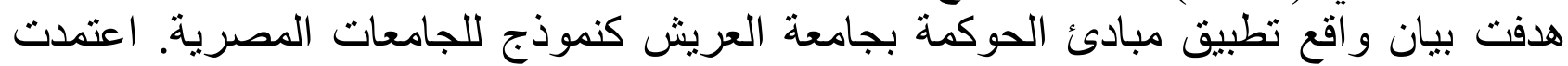

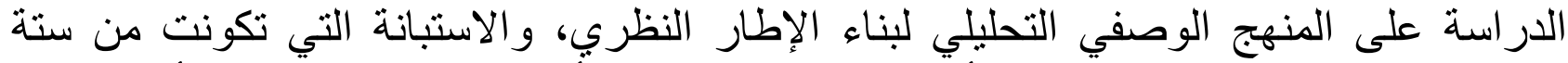

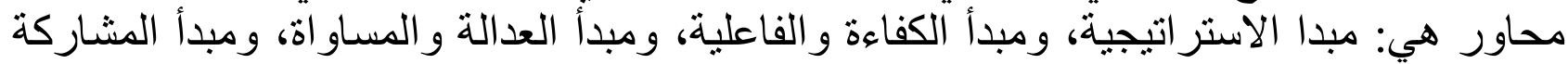

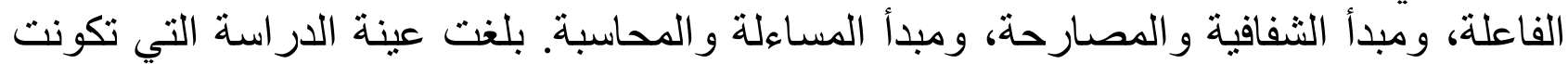

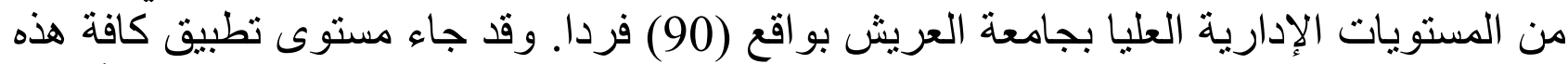

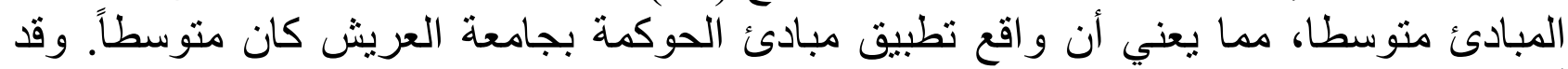

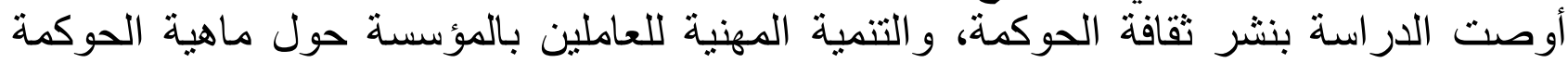
ومتطلباتها و أليات تطبيقها، إنشاء مركز خاص باص بالجامعة.

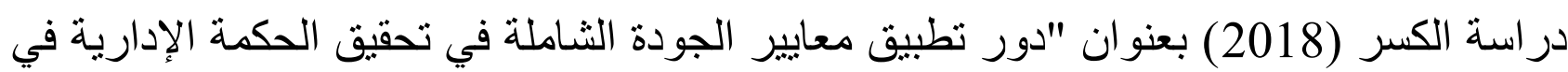

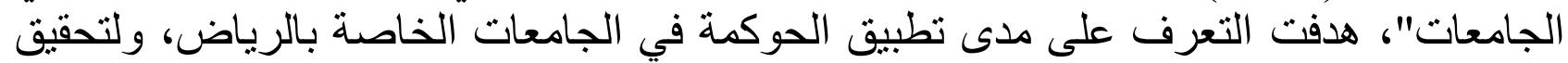

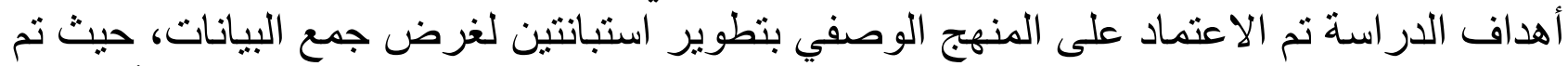

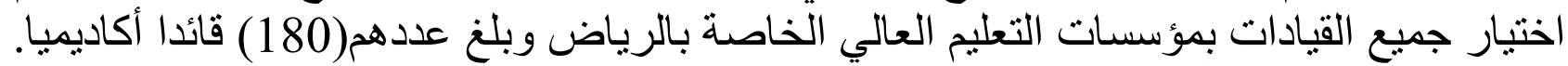

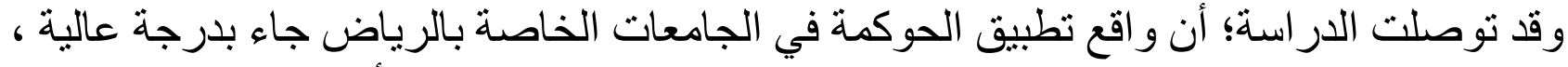

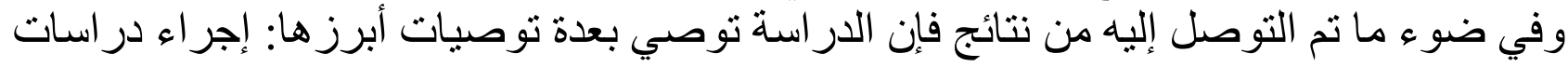

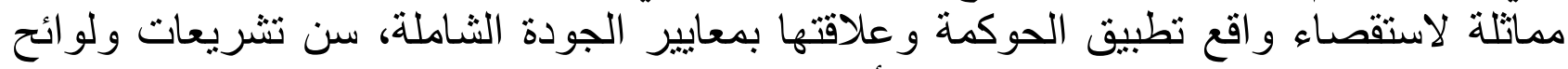

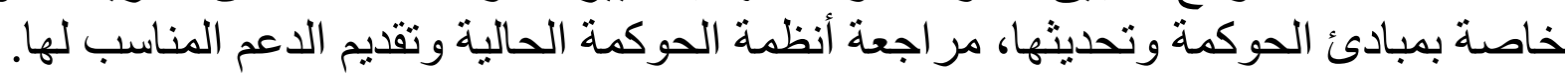

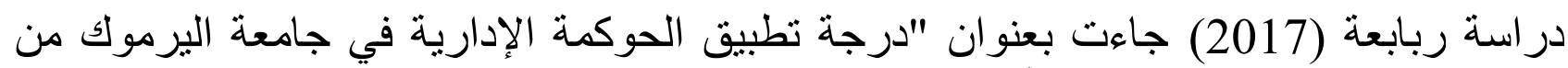

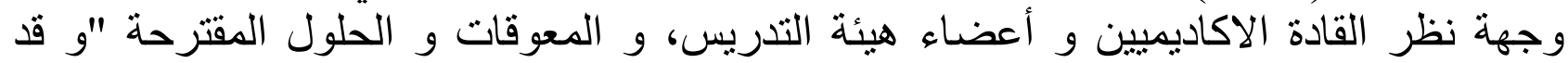




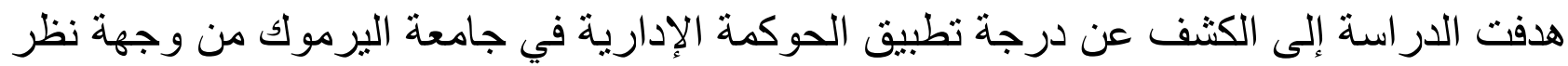

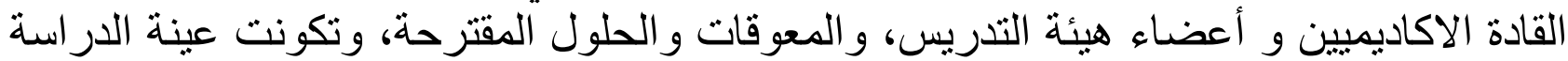

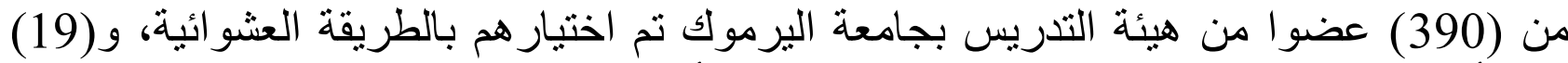

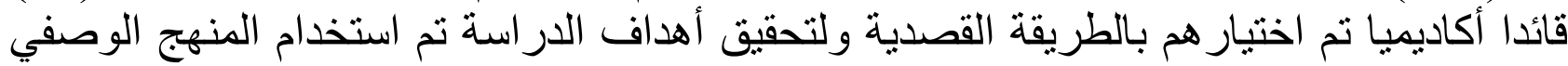

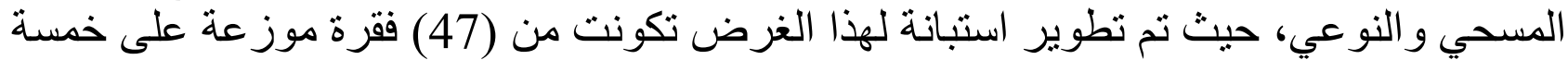

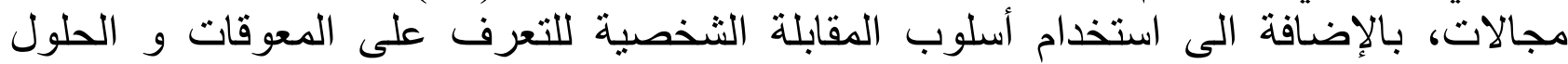

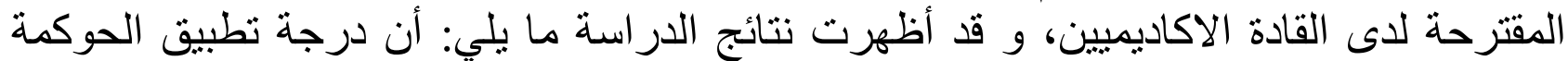

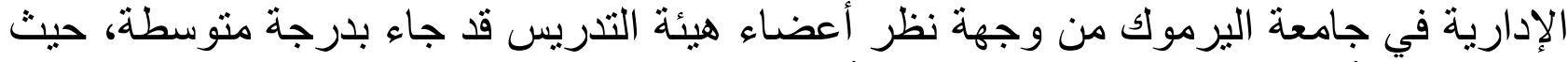

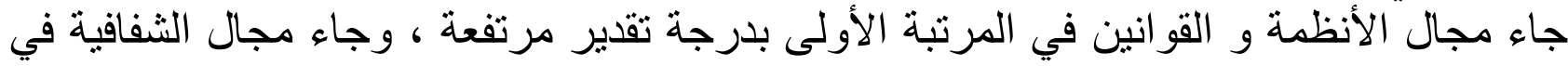

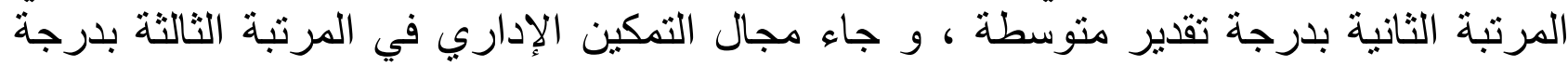

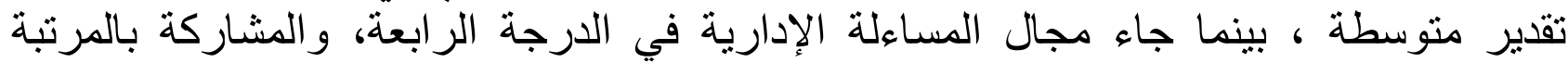

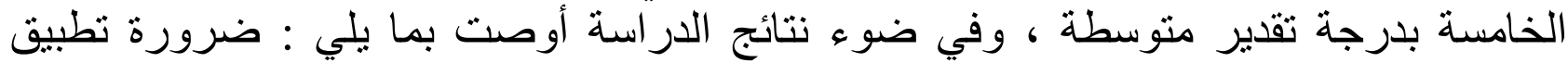

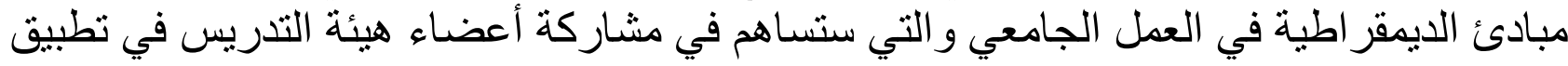

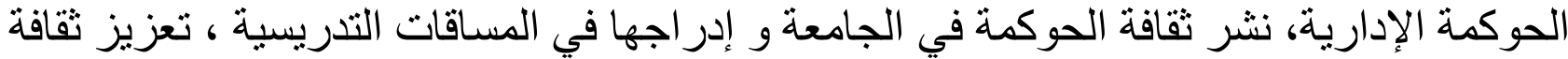
المساءلة في الجامعة الإدة،

در اسة إغنس (2017) Patricia Agnes "نحو الحوكمة الرشيدة و إدارة جامعات غرب ألخدة أفريقيا"، هدفت

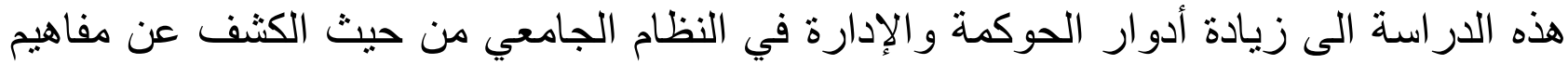

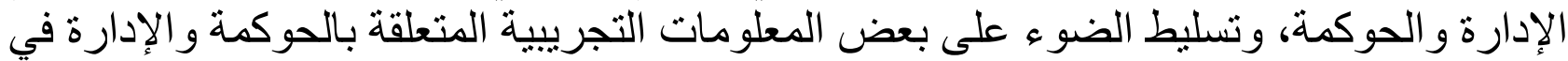

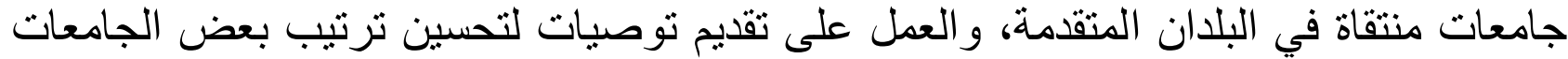

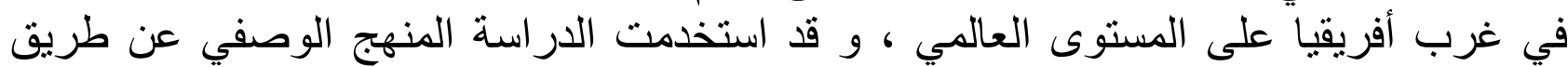

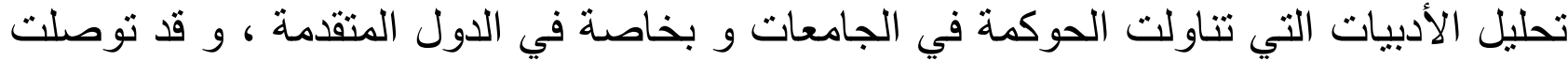

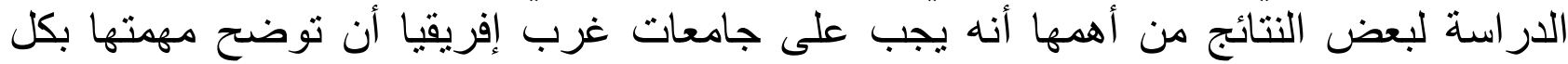

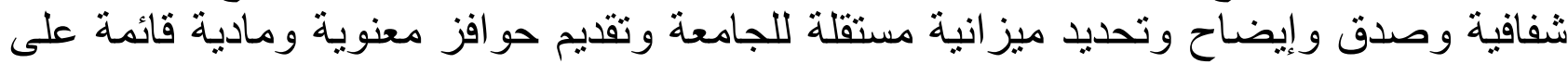

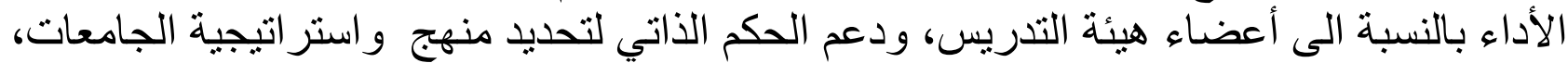

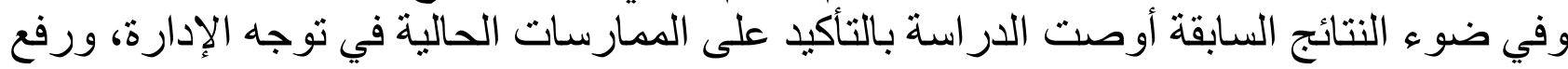

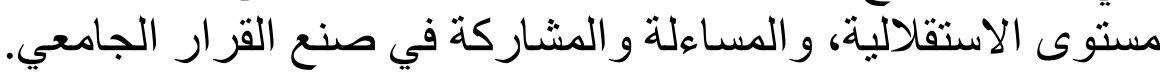

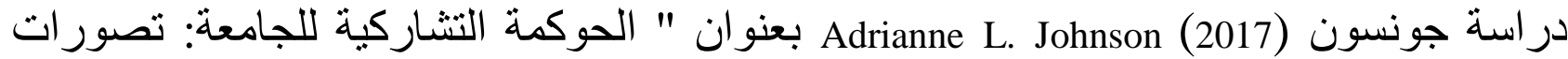

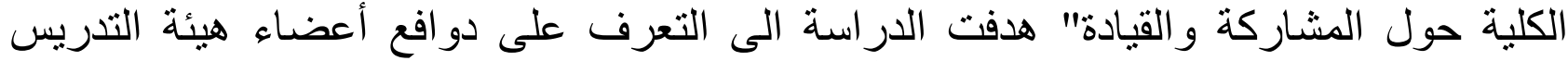

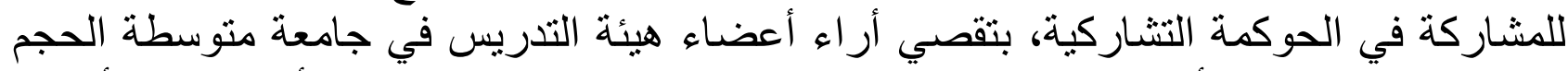

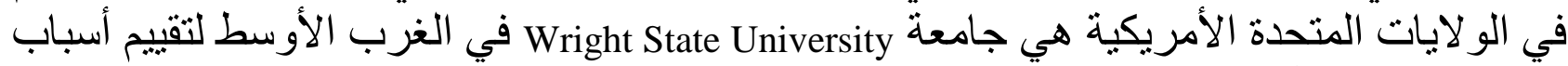

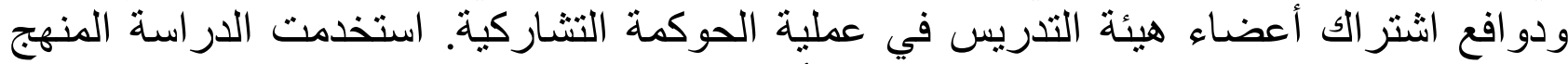

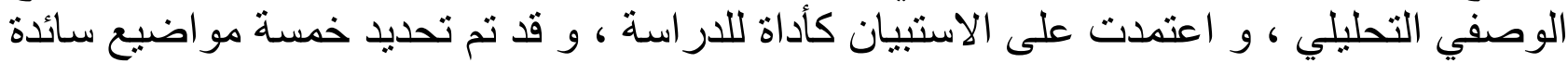

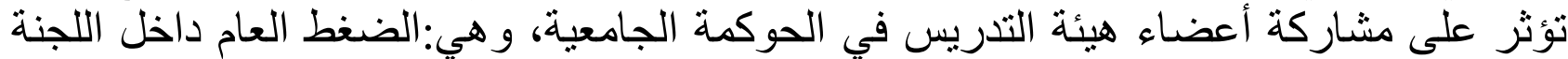

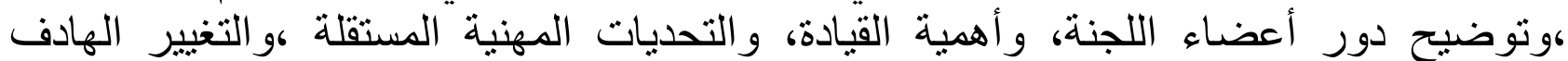
و النجاح التنظيمي، وتوصلت الدر اسة الى بعض النتائج والتوصيات من أهمها: تقدير أعضاء هيئة التهاء

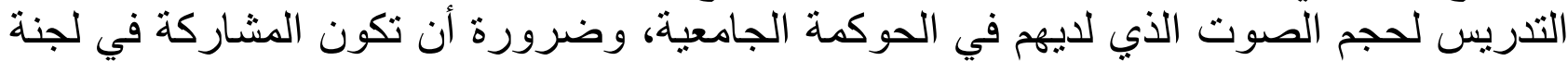

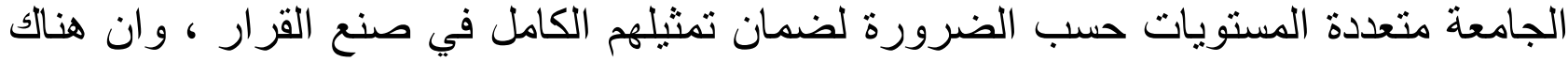


حاجة إلى صقل الممارسة المعتادة للحوكمة الجامعية و التغلب على تعقيدات هذا التطبيق. منهجية الدراسة وإجراء|تها:

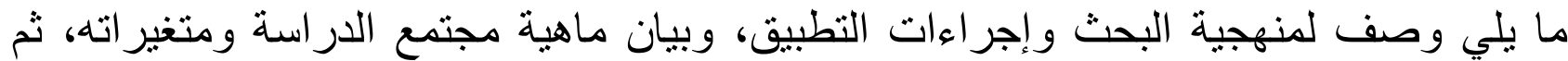
تفصيل عينة الدر اسة وكيفية احتسابها، وكذللك بيان أداة الدراسة وآلية آلية بنائها و أقسامها و أبعادها،

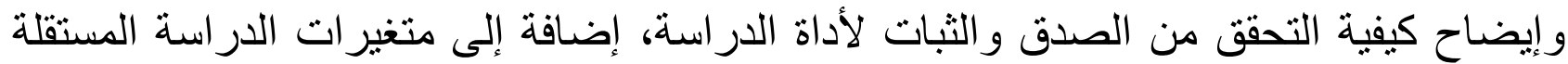

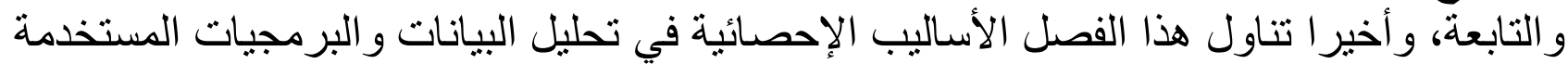
في البحوث الكمية.

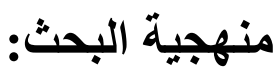

اعتمدت هذه الدراسة على المنهج الوصفي التحليلي لتحقيق أهدافها، كون هذا المنهج لا يقتصر

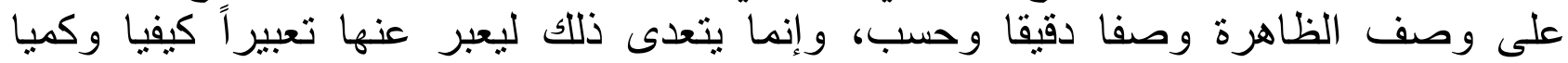

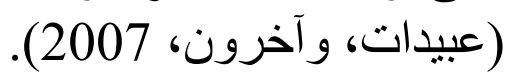

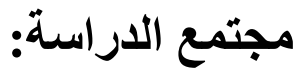

تكون مجتمع الدراسة المستهدفين ببرامج التنمية البشرية (في قطاع التأهيل) بوزارة التربية

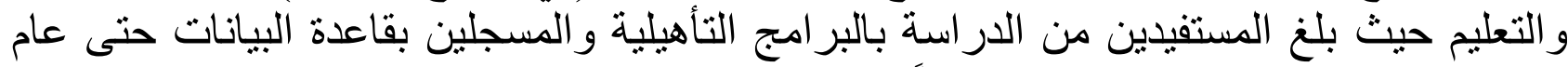

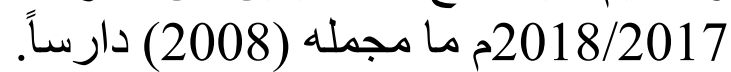

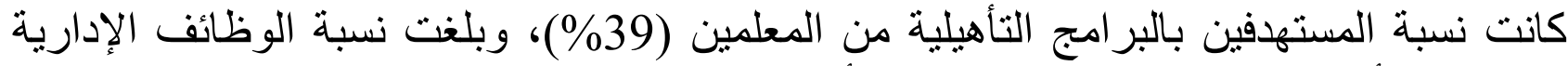

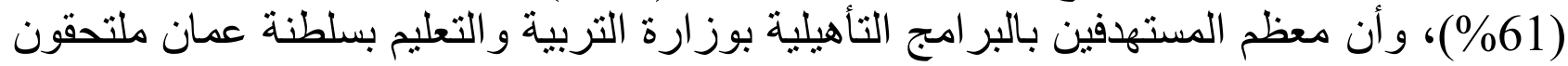

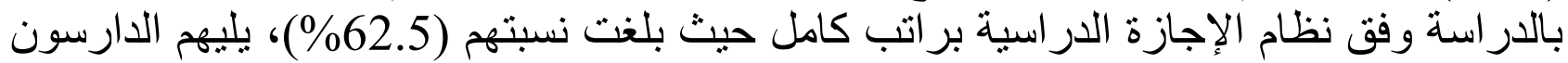

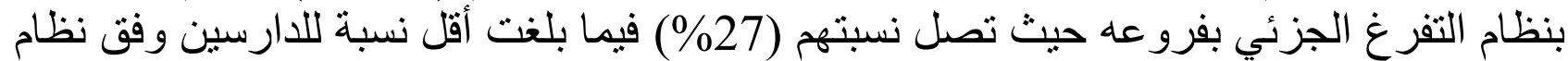

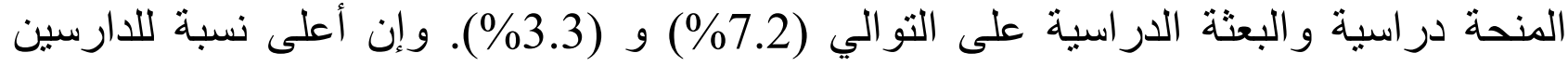

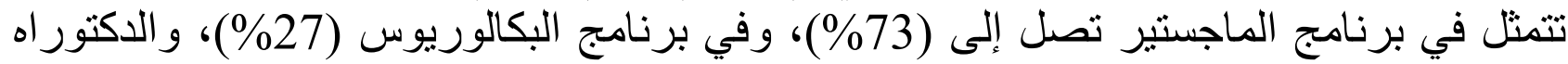

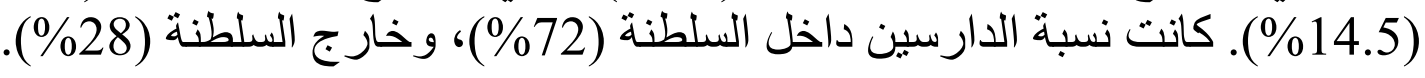

\section{عينة الاراسة}

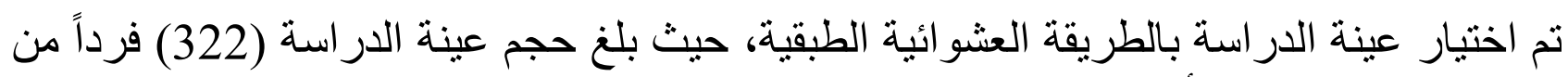

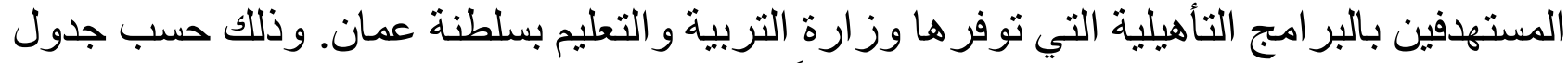

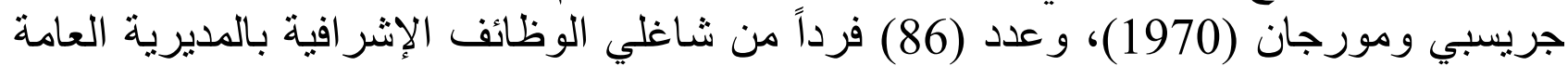
لتنمية الموارد البشرية إضافة إلى خمس محافظات.

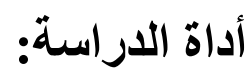

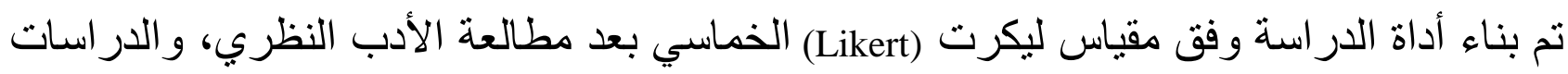

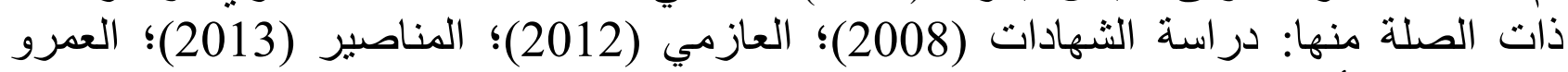

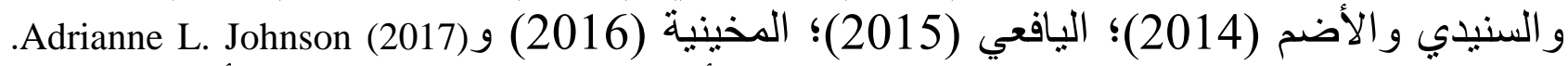
تضمنت الاستبانة (49) عبارة توزعت في خمسة أبعاد هي: مبادئ الحوكمة الأربعة التي تم 


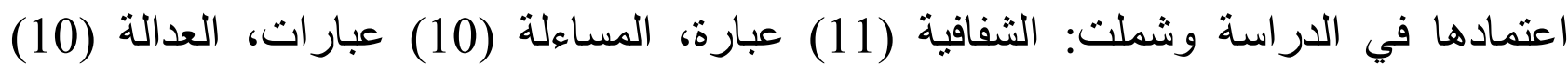

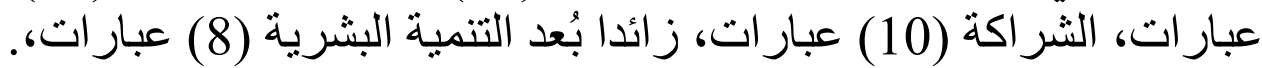
صدق الأداة: تم التحقق من الصدق الظاهري و الصدق البنائي

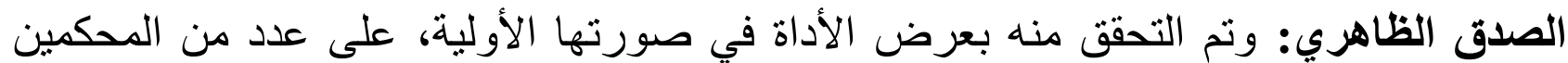

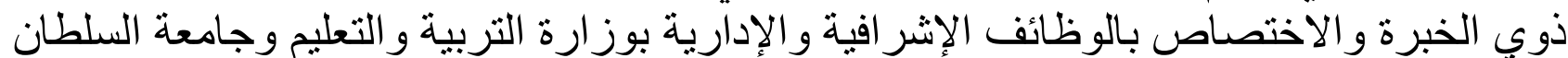

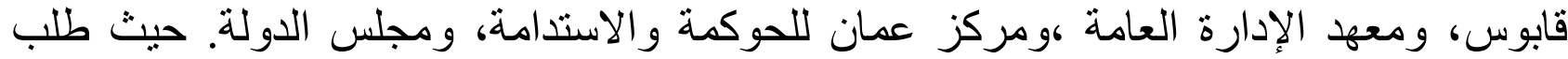

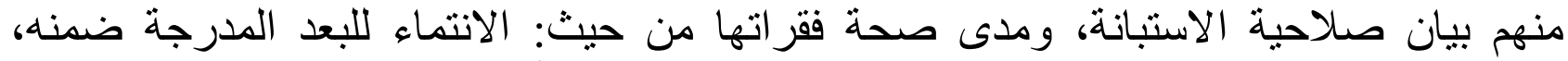

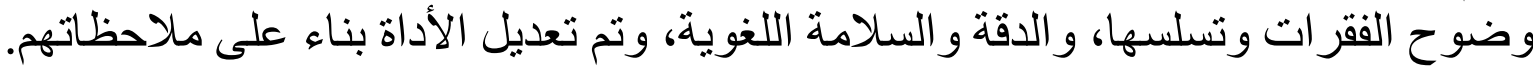

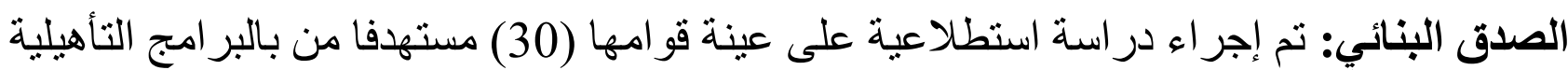

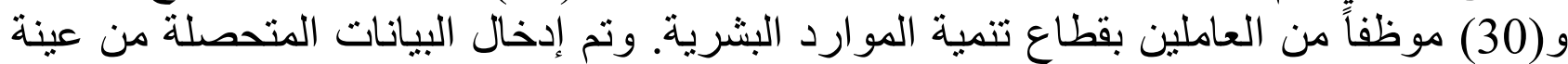

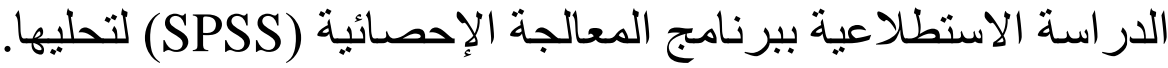
ثبات أداة الدراسة: للتحقق من ثبات الاستبانة نم احتساب معامل الاتساق الداخلي للأبعاد الخمسة لإنة

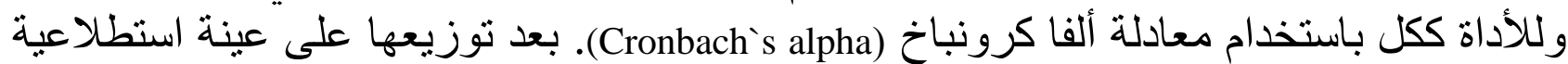

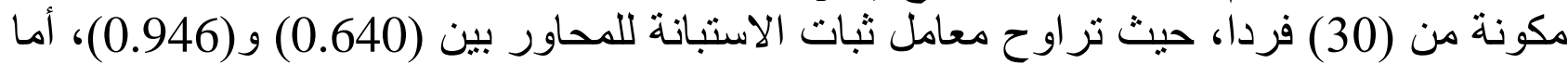

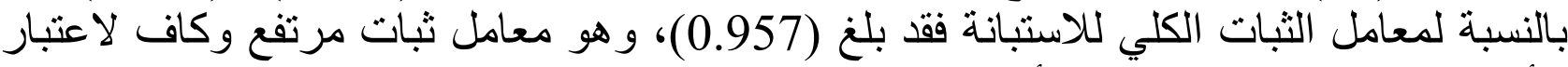

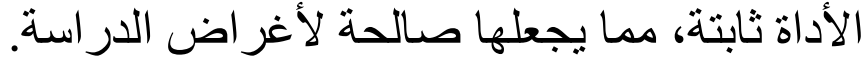

أساليب المعالجة الإحصائية: - الرزمة الإحصائية للعلوم الاجتماعية (SPSS) في تحليل البيانات التي سيتم جمعها بعد تطبيق الاستبانة. - معامل ألفا كرونباخ لإجر اء اختبار الثبات لفقرات الاستبانة أداة البحث.

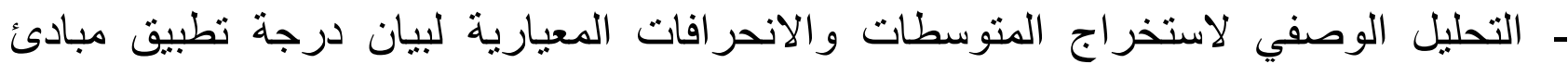
الحوكمة في قطاع التأهيل. - تحليل التباين الأحادي (One-Way Anova)، اختبار شيفيه (Scheffe) للعينات المستقلة للتحقق من الفروق ذات الدلالة الإحصائية في تطبيق مبادئ (Independent-Samples T Test) الحوكمة في قطاع التأهيل).

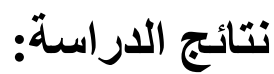

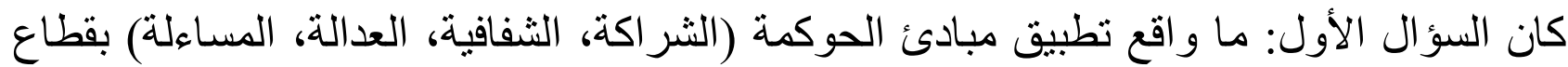
التأهيل بوزارة التربية و التعليم وجهة نظر المستهدفين بالبر امج التأهيلية (الدكتور اه ـ الماجستير-

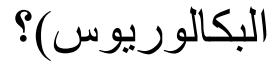

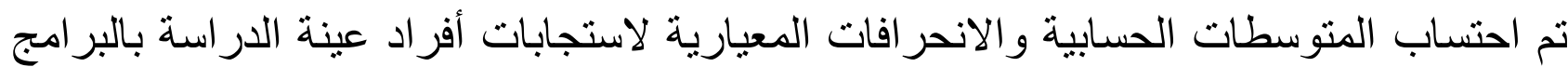

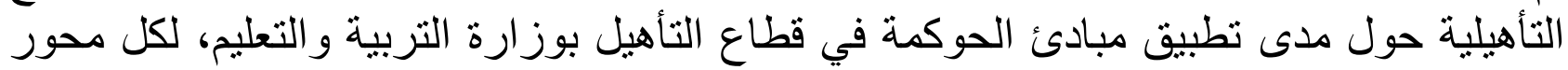

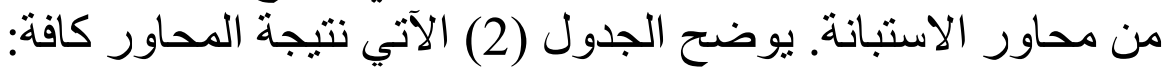
جدول (1) مدى تطبيق مبادئ الحوكمة في قطاع التأهيل بوز ارة التربية و التعليم (ن*=-322) 
IJASOS- International E-Journal of Advances in Social Sciences, Vol. VI, Issue 17, August 2020

\begin{tabular}{|c|c|c|c|c|}
\hline المستوى & المعياري & المتوسط الحسابي & مبادئ الحوكمة & الرتبة \\
\hline متوسط & 0.76 & 3.22 & الثفافية & 1 \\
\hline متوسط & 0.82 & 3.02 & 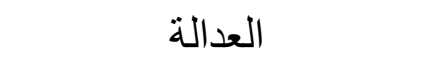 & 2 \\
\hline متوسط & 0.77 & 2.94 & المساءلة & 3 \\
\hline متوسط & 0.72 & 2.82 & 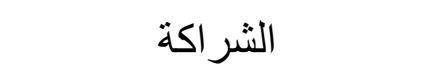 & 4 \\
\hline متوسط & 0.68 & 2.99 & تطبيق مبادئ الحوكمة ككل & \\
\hline
\end{tabular}

يتضح من الجدول (1) أن المستوى العام حول تطبيق مبادئ الحوكمة في قطاع التأهيل بوزارة التباء

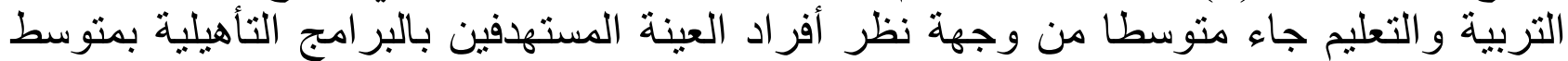

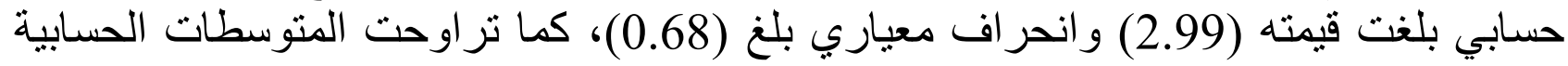
لاستجابات هذه الفئة من العينة لواقع تطبيق مبادئ الحئ الحوكمة بين (2.82-

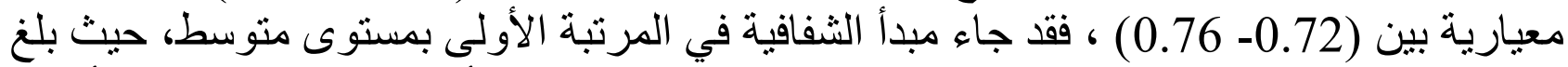

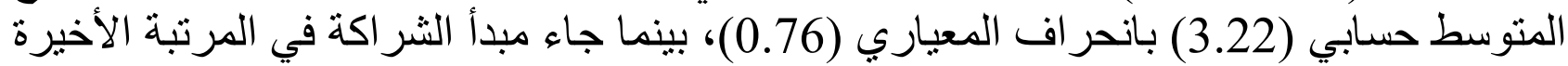

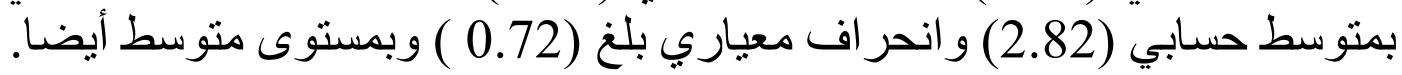

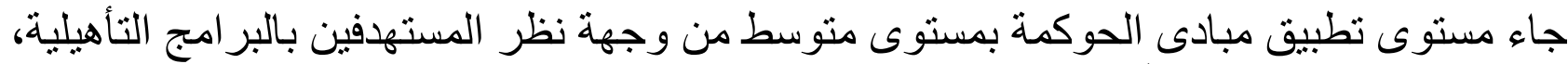

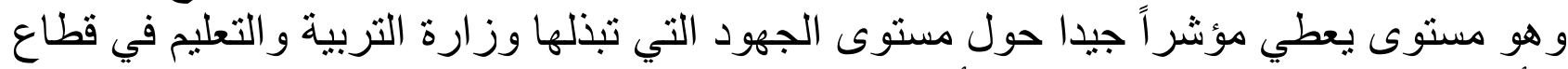

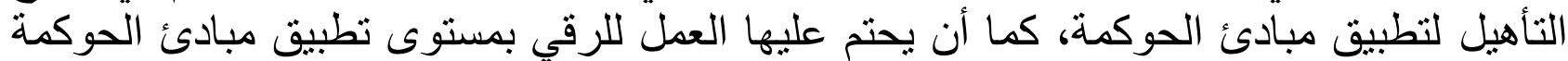

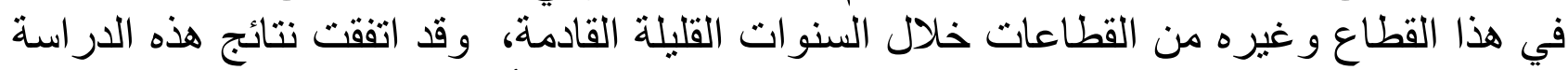

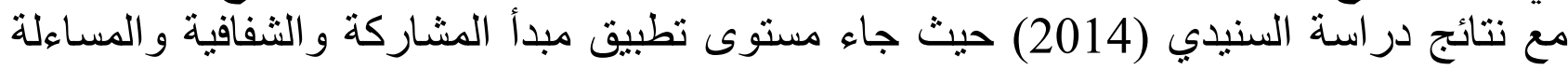
فيها بمستوى متوسط بما ينو افق ونتائج هذه الدراسة من العينتين ودر اسة رباء ربابعة (2017) حيث ظهر فيها مستوى تطبيق الحوكمة منوسطا.

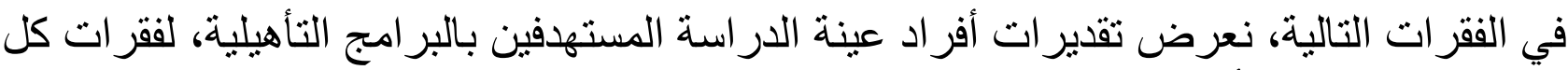

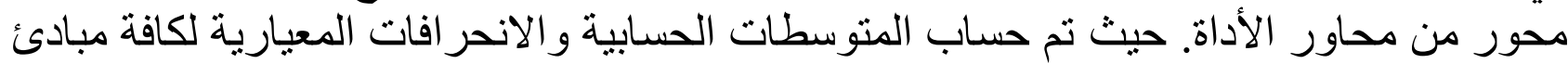
الحوكمة كل على حدة، فجاءت الأد النتائج كالآتي:

نتائج المحور الأول: الثفافية

جدول (2) المتوسطات الحسابية و الانحر افات المعيارية لفقر ات مبدأ الثفافية (ن*=322)

\begin{tabular}{|c|c|c|c|c|}
\hline 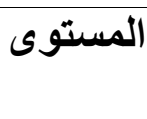 & الالاحيراف & الحستبي & الفقرات & $ت$ \\
\hline 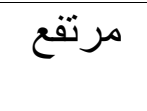 & 1.05 & 3.66 & تُعبر البو ضبة التعليمية. الترح لكافة البر امج و الأنظمة الدر اسية بشفافية & 1 \\
\hline مرتفع & 0.95 & 3.50 & تُشُشر القر ارات المتعلقة بالقطاع على رابط خاص في البوابة & 2 \\
\hline
\end{tabular}




\begin{tabular}{|c|c|c|c|c|}
\hline & & & التعليمية وفق المستجدات & \\
\hline مرتفع & 1.02 & 3.45 & يقدم لي العاملون بالقطاع معلومات مفصلة عن أي استفسار اتي & 3 \\
\hline متوسط & 1.04 & 3.20 & يتم الإفصاح عن أية قر ار ات جديدة ذات علاقة بقطاع التأهيل & 4 \\
\hline متوسط & 1.07 & 3.13 & 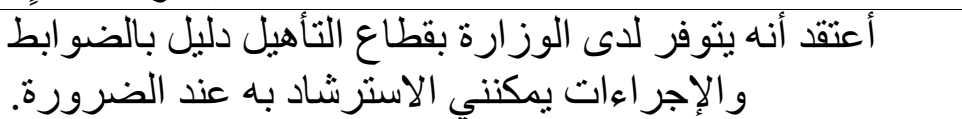 & 5 \\
\hline متوسط & 1.04 & 3.13 & يتسم نمط التعامل معي في قطاّع التأهيل بالانفتاح و الوضو ح. & 6 \\
\hline متوسط & 1.03 & 3.08 & 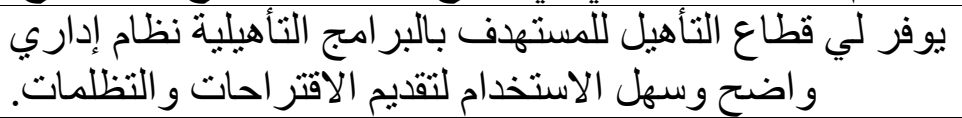 & 7 \\
\hline متوسط & 1.13 & 3.07 & أجد أن الأنظمة و القوانين المطبقة في قطاع التأهيل تتسم & 8 \\
\hline متوسط & 1.04 & 3.06 & 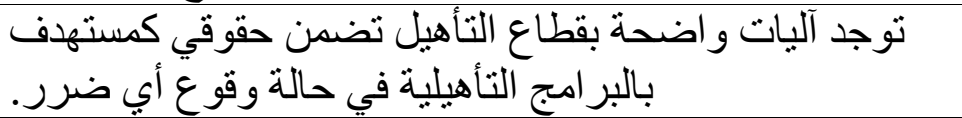 & 9 \\
\hline متوسط & 1.08 & 2.90 & يتم تزويدي كمستهدف بالمعلومات و المستجدات المتعلقة & $\begin{array}{l}1 \\
0\end{array}$ \\
\hline متوسط & 0.76 & 3.22 & مبدأ المساعلة ككل & \\
\hline
\end{tabular}

يتضح من الجدول (2) أن مستوى مبدأ الثفافية ككل جاء متوسطاً؛ حيث بلغ المتوسط الحسابي

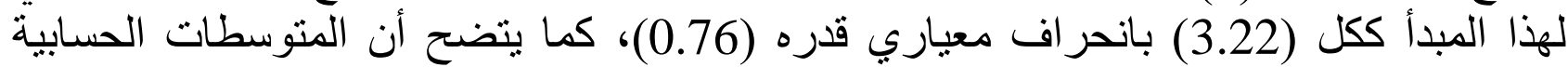

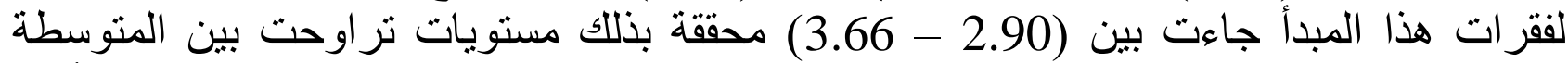

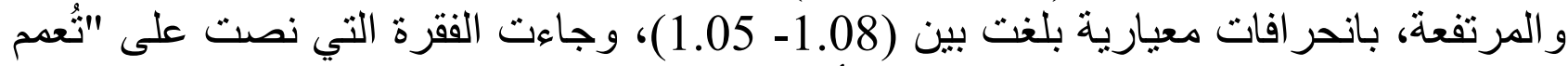

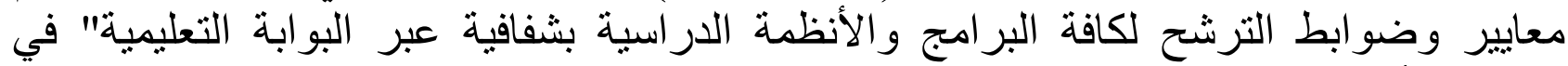

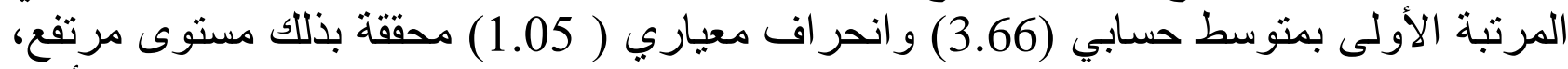

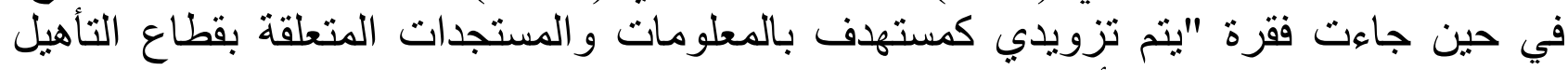
بصفة مستمرة." بالمرتبة الأخيرة بمتوسط حسابي بلغ (2.90) و وانحر اف معياري بلغ (1.08) بمستوى متوسط.

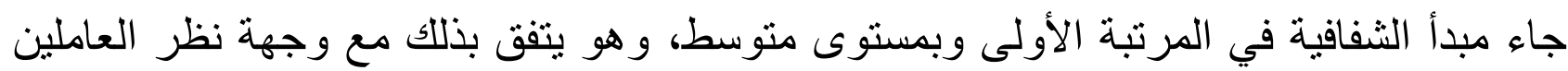

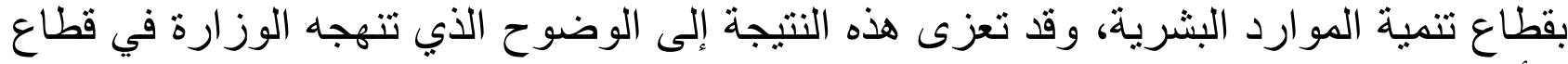

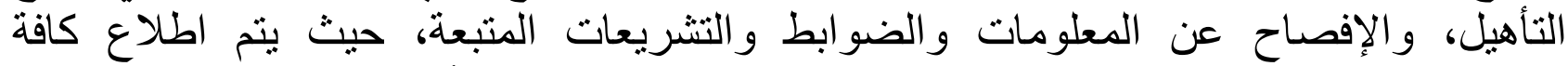

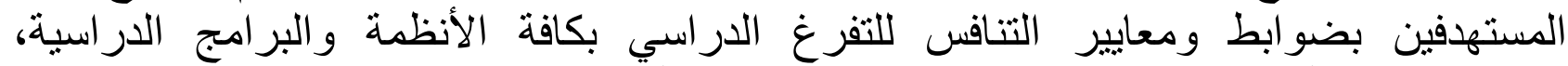

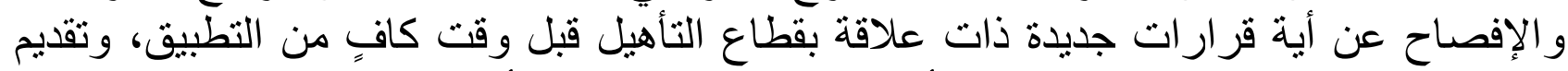

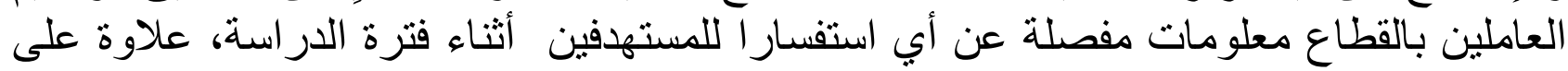

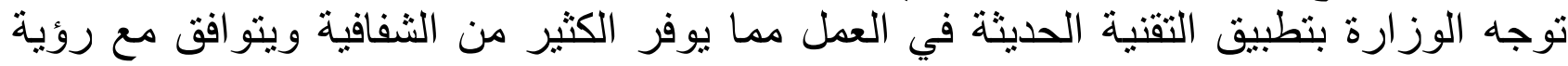

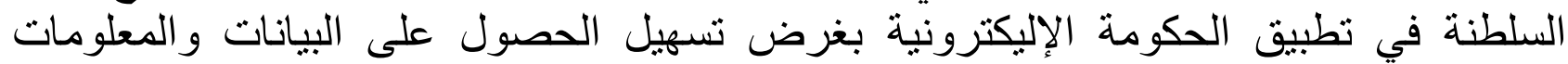

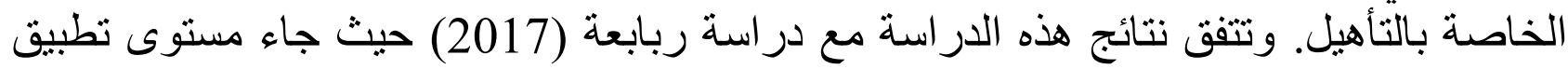
مبدا الثفافية فيها بمستوى متوسط. تئن 


\section{نتائج المحور الثاني: العدالة}

جدول (3) المتوسطات الحسابية و الانحر افات المعيارية لفقر ات مبدأ العدالة (ن*=322)

\begin{tabular}{|c|c|c|c|c|}
\hline المستوى & المعياري - الاف & المتوسط & الفقرات & 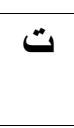 \\
\hline منوسط & 1.12 & 3.12 & مصلحة قطاع التأهيل. أرى تلى تفعيل مبدأ تقديم المصلحة العامة على & 1 \\
\hline متوسط & 1.04 & 3.09 & 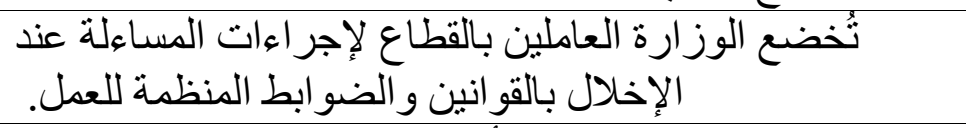 & 2 \\
\hline متوسط & 1.06 & 3.03 & 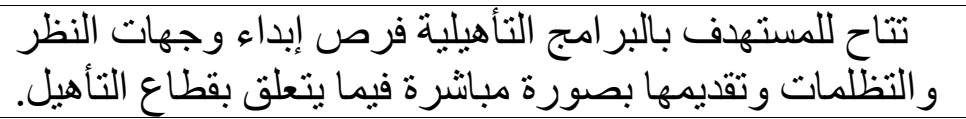 & 3 \\
\hline متوسط & 0.97 & 3.02 & يمارس قطاع التاهيل مسؤولياته في المساءلة الإدارية بصونة فاقدة. & 4 \\
\hline متوسط & 1.08 & 2.97 & 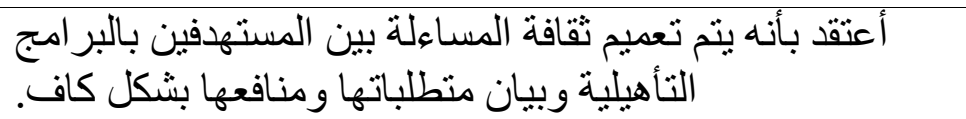 & 5 \\
\hline متوسط & 1.06 & 2.94 & الأنظمة و القو انين المعمول بها تضمن تحقيق مستوى مناسب & 6 \\
\hline متوسط & 0.95 & 2.89 & $\begin{array}{l}\text { يمتلك قطاع التأهيل دليلا عمليا نافذ للمساءلة الإدارية للعاملين } \\
\text { بالقطاع. }\end{array}$ & 7 \\
\hline متوسط & 0.95 & 2.88 & أرى أن آليات الدساءلة المطبقة بالقطاع تتسم بالموضو عية. & 8 \\
\hline متوسط & 1.15 & 2.87 & يحق للمستهدف مساءلة كافة المستويات الإدارية في الإخلإل & 9 \\
\hline متوسط & 1.03 & 2.78 & 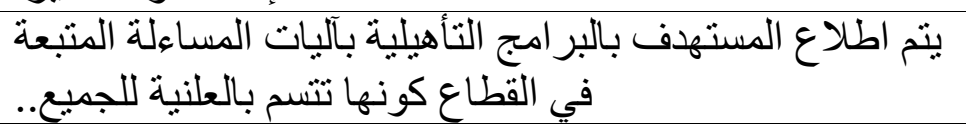 & 10 \\
\hline متوسط & 1.06 & 2.73 & تفصح الوزارة عن آليات المساءلة والمحاسبة الإدارية المتبعة & 11 \\
\hline متوسط & 0.77 & 2.94 & مبدأ المساعلة ككل & \\
\hline
\end{tabular}

يتبين من الجدول (3) أن المتوسط الحسابي لمبدأ العدالة ككل بلغ (3.02) و انحر افت معياري قدره

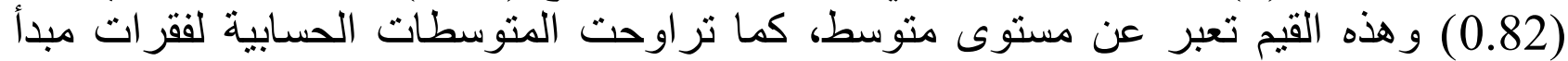

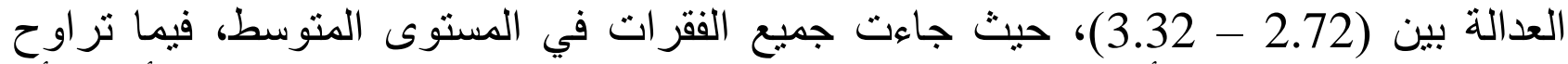

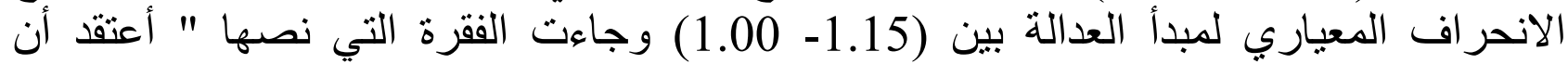

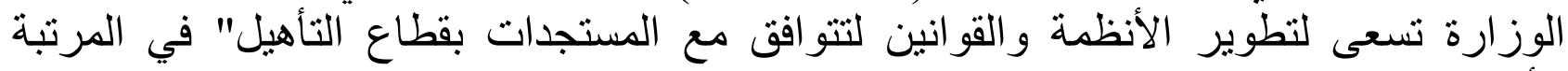

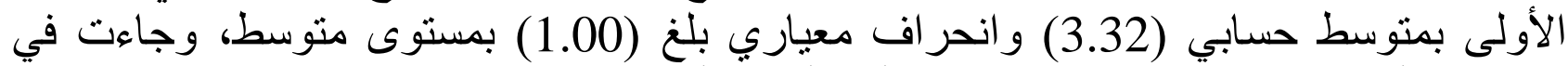

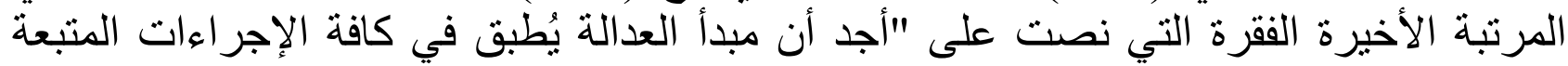

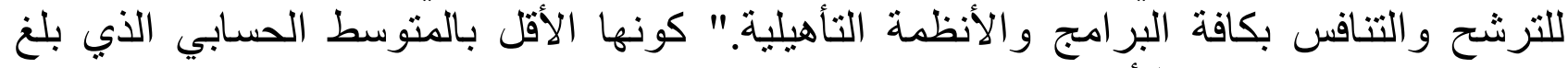
(2.72) وبمسنوى منوسط أيضا.

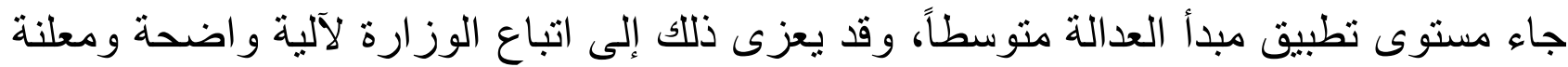

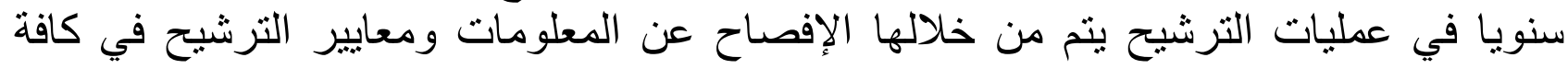




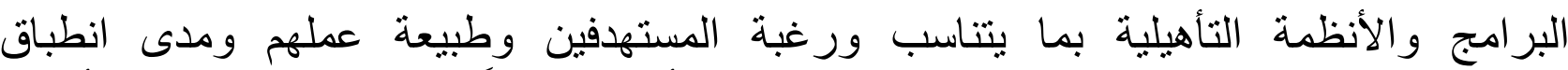

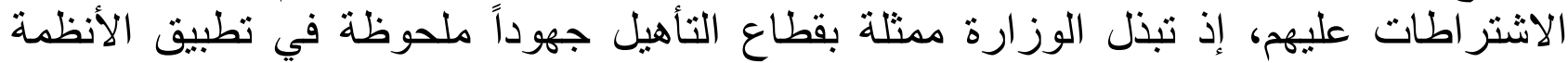

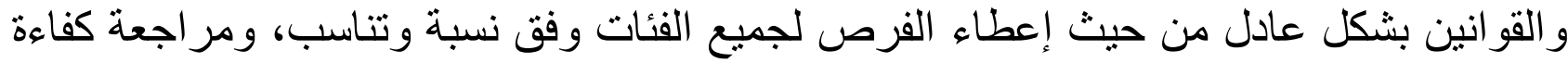
وكفاية التشريعات والإجراءات القانونية والضوابط إنطات بما بساعد على صحة اتخاذ القرارات فيما يتعلق بالعملية التأهيلية.

\section{نتائج المحور الثالث: المساءلة بالةهائة}

جدول (4) المتوسطات الحسابية و الانحر افات المعيارية لفقرات مبدأ المساءلة (ن=322)

\begin{tabular}{|c|c|c|c|c|}
\hline المستوى & الانحر افع المعاري & المتوسط الحسب & الفقرات & ت \\
\hline متوسط & 1.12 & 3.12 & أرى الوز ارة تؤكد على تفعيل مبدأ تقديم المصلحة العامة على & 1 \\
\hline متوسط & 1.04 & 3.09 & 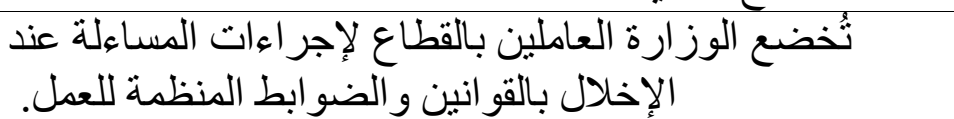 & 2 \\
\hline متوسط & 1.06 & 3.03 & 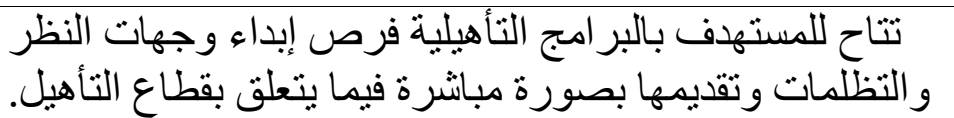 & 3 \\
\hline متوسط & 0.97 & 3.02 & يمارس قطاع التأهيل مسؤولياته في المساءلة الإدارية بصورة & 4 \\
\hline متوسط & 1.08 & 2.97 & 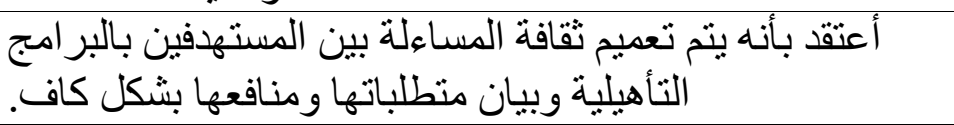 & 5 \\
\hline متوسط & 1.06 & 2.94 & الأنظمة و القوانين المعدول بها تضمن تحقيق مستوى مناسب & 6 \\
\hline متوسط & 0.95 & 2.89 & $\begin{array}{l}\text { يمتلك قطاع التأهيل دليلا عمليا نافذ للمساءلة الإدارية للعاملين } \\
\text { بالقطاع. }\end{array}$ & 7 \\
\hline متوسط & 0.95 & 2.88 & أرى أن آليات المساءلة المطبقة بالقطاع تتسم بالموضو عية. & 8 \\
\hline متوسط & 1.15 & 2.87 & 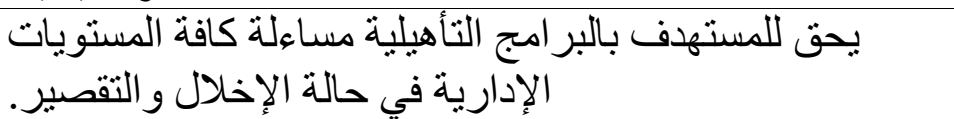 & 9 \\
\hline متوسط & 1.03 & 2.78 & 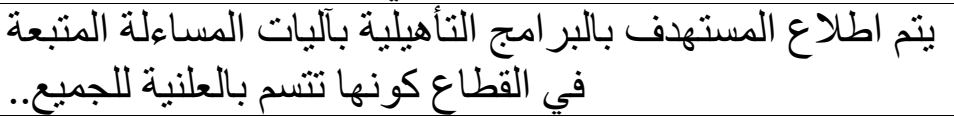 & $\begin{array}{l}1 \\
0\end{array}$ \\
\hline متوسط & 1.06 & 2.73 & تفصح الوزارة عن آليات المساءلة و المحاسبة الإدارية المتبعة في فطاع التهيل & $\begin{array}{l}1 \\
1\end{array}$ \\
\hline متوسط & 0.77 & 2.94 & 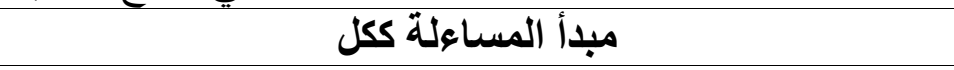 & \\
\hline
\end{tabular}

يبين الجدول (4) أن المتوسط الحسابي لمبدأ المساءلة ككل وفقا لاستجابات المستهدفين بالبر امج

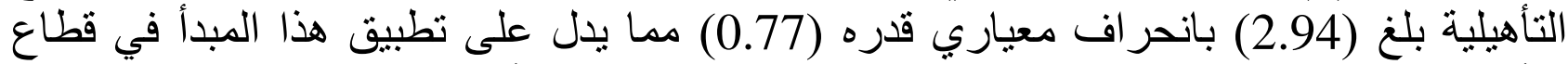

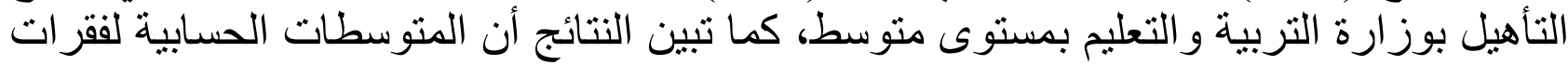

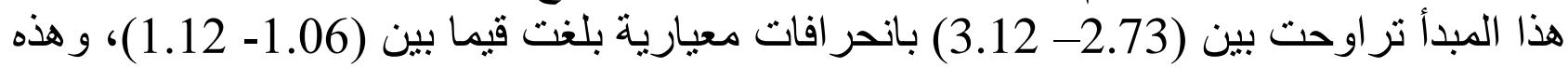

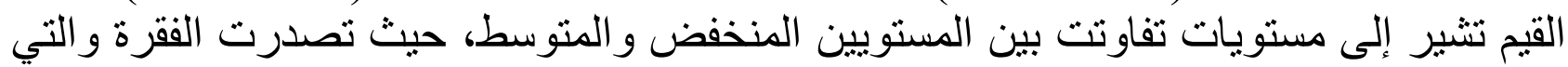
نصها " أرى أن الوزارة تؤكد على تفعيل مبدأ تقديم المصلحة العامة على المصلحة بقلى بقطاع 
التأهيل" المرتبة الأولى بمتوسط حسابي (3.12) و انحراف معياري قدره (1.12) بمستوى

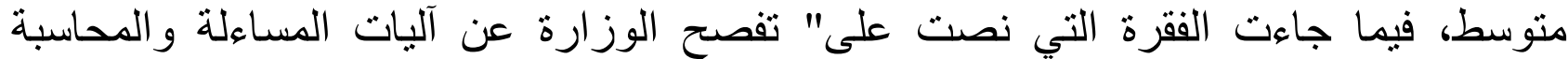

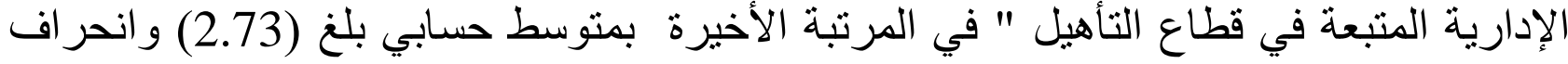

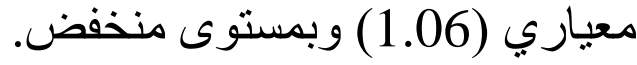

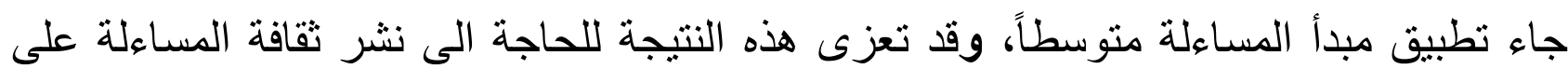

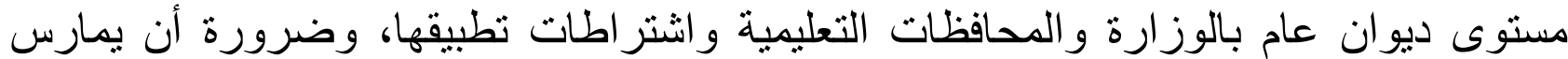

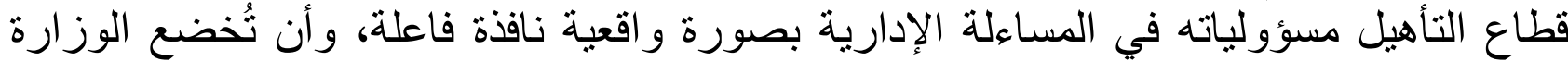

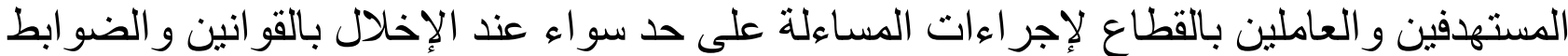

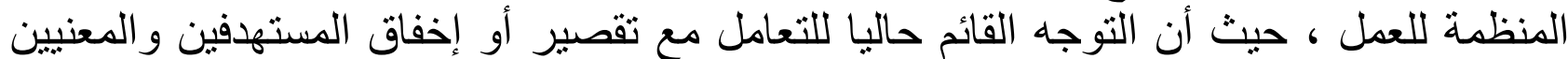

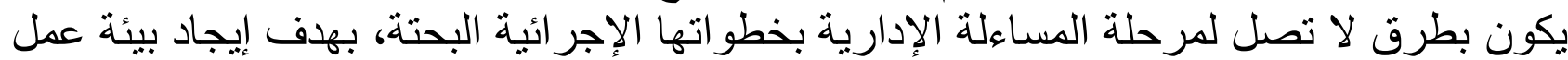

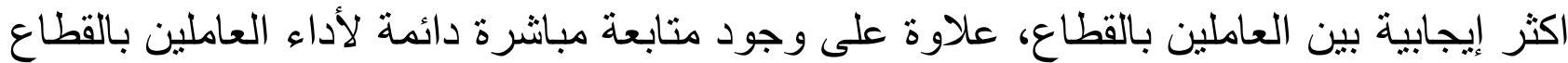

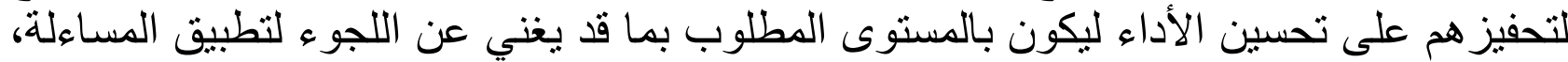

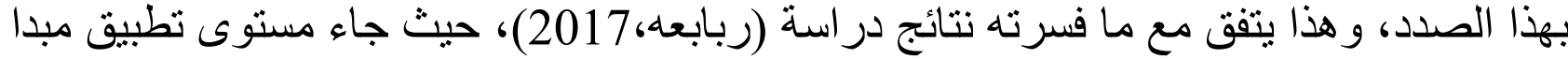
المساءلة فيها بمستوى منوسط بما يتو افق ونتائج هذه الدر اسة.

$$
\text { نتائج المحور الرابع: الشراكة }
$$

جدول (5) المتوسطات الحسابية و الانحر افات المعيارية لفقر ات مبدأ الثر اكة (ن=322)

\begin{tabular}{|c|c|c|c|c|}
\hline 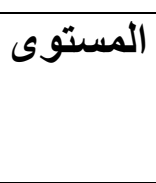 & المعياري & 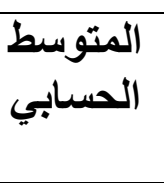 & 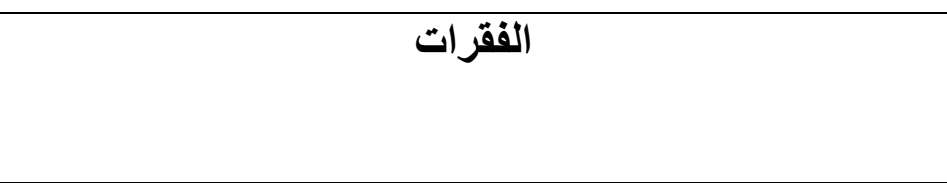 & 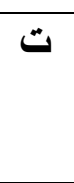 \\
\hline مرتفع & 1.08 & 3.81 & 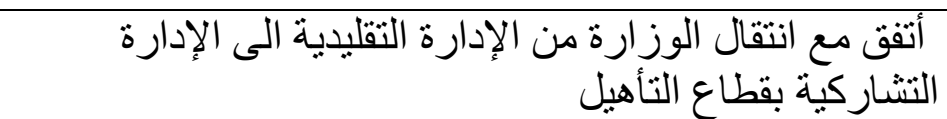 & 1 \\
\hline 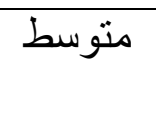 & 1.10 & 3.15 & التوفنين بق الوز ارة نظأهل اتصـال مُيسر ومفتوح بيني وبين & 2 \\
\hline 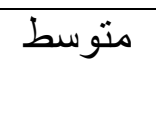 & 1.04 & 3.07 & 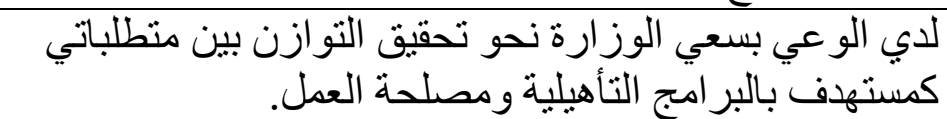 & 3 \\
\hline متوسط & 1.10 & 3.06 & 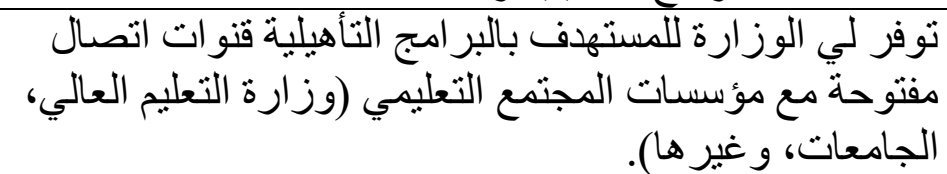 & 4 \\
\hline متوسط & 1.13 & 2.73 & 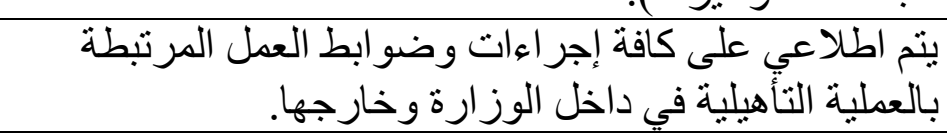 & 5 \\
\hline 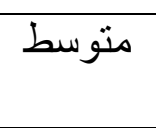 & 1.18 & 2.67 & 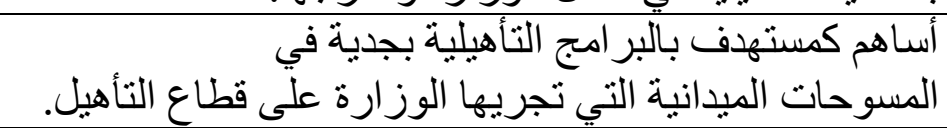 & 6 \\
\hline 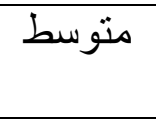 & 1.10 & 2.61 & 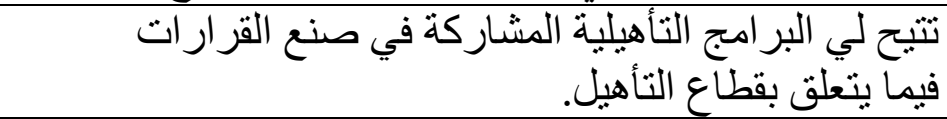 & 7 \\
\hline منخفض & 1.06 & 2.51 & 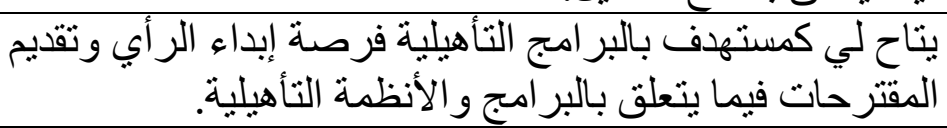 & 8 \\
\hline منخفض & 1.02 & 2.50 & 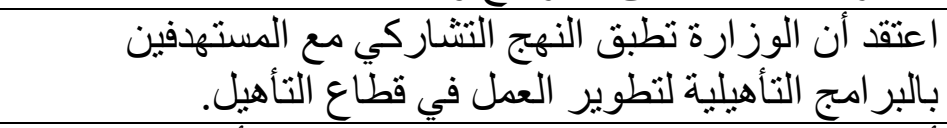 & 9 \\
\hline منخفض & 1.10 & 2.49 & أققو بدور فعّال في تقييم مدى تحقيق الوز ارة لأهداف البر امج & 10 \\
\hline
\end{tabular}




\begin{tabular}{|c|c|c|c|c|}
\hline & & & التأهيلية. & \\
\hline منخفض & 1.09 & 2.40 & 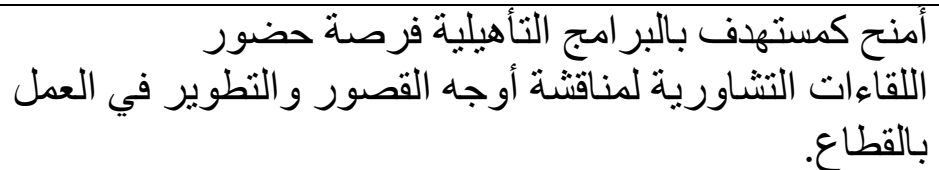 & 11 \\
\hline متوسط & 0.72 & 2.82 & مبدأ الشراكة ككل & \\
\hline
\end{tabular}

يتبين من الجدول (5) أن المتوسط الحسابي لمبدأ الثر اكة ككل بلغ (2.82) بانحر اف معياري قدره

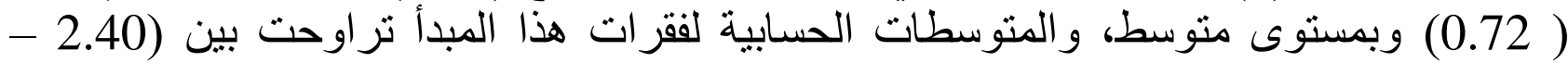

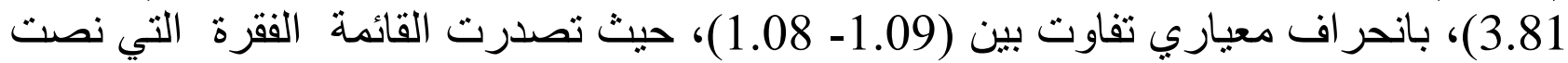

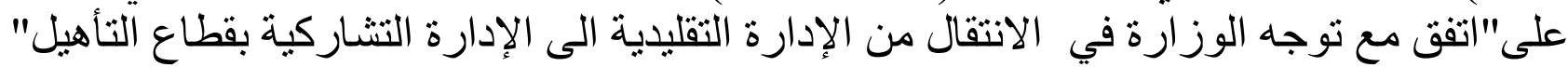

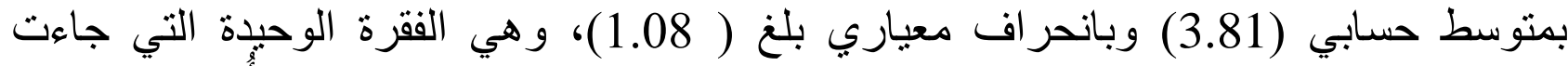

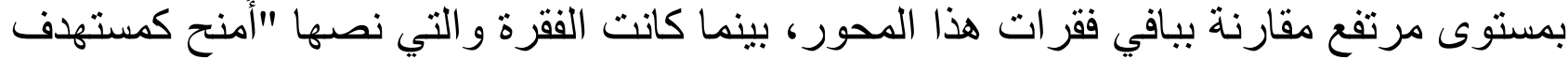

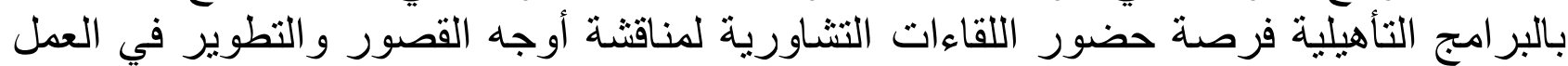
بالقطاع" هي الأقل بالمتوسط الحسابي الذي بلغ (2.40) وبانحراف معياري قدره (1.09) وبمستوى منخفض.

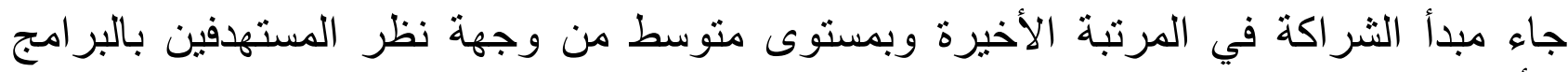

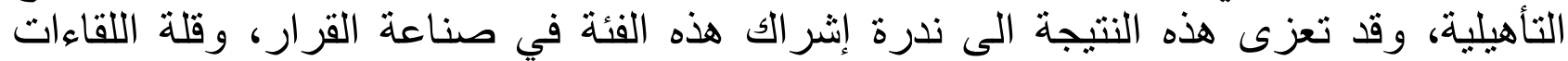

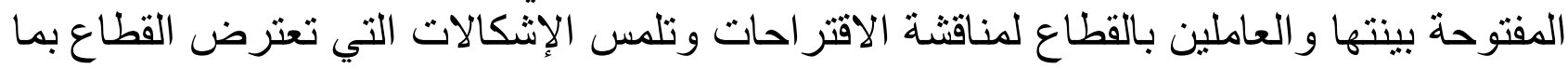

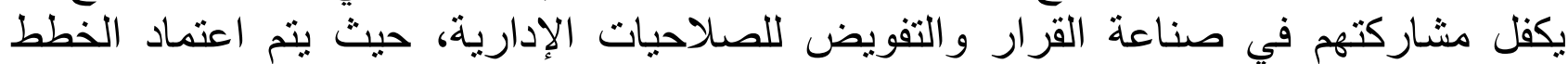

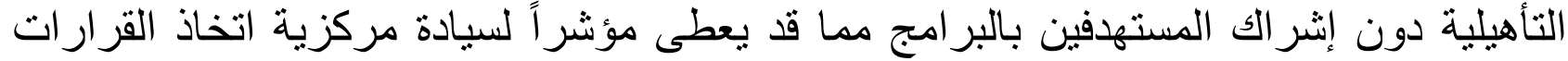

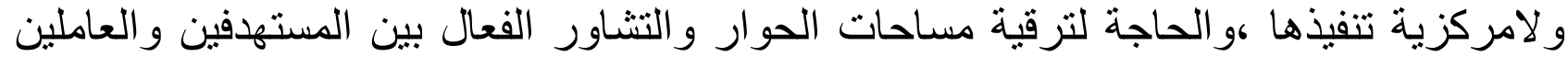

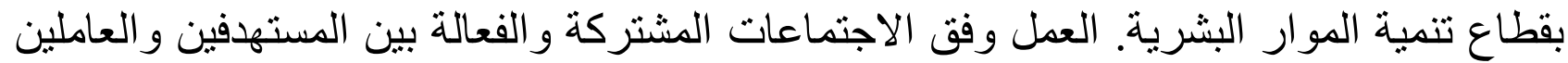

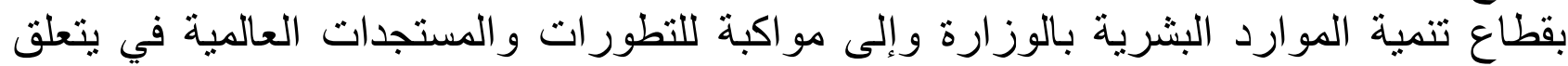
بأنظمة الإدارة الحديثة.

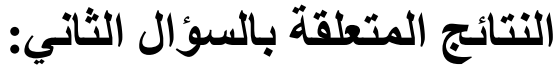

ماهي التحديات التي نو اجه وزارة التربية و التعليم في تطبيق مبادئ الحوكمة (الثر اكة، الثفافية،

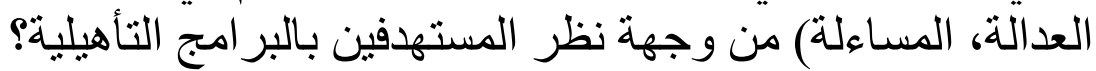

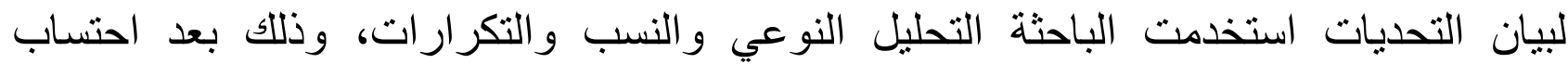

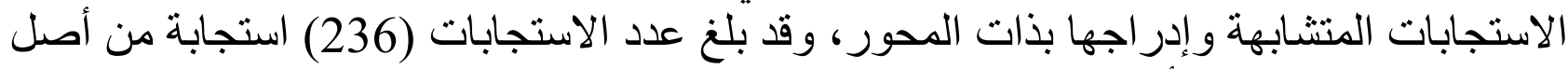
(322)، كما في الجدول أدناه.

جدول (7) التحديات التي تو اجه وز ارة التربية والتعليم في تطبيق مبادئ الحوكمة من وجهة المستهدفين بالبر امج التأهيلية التية

التحديات التي تواجه وزارة التربية والتعليم في تطبيق مبادئ الحوكمة التكرارات 
IJASOS- International E-Journal of Advances in Social Sciences, Vol. VI, Issue 17, August 2020

\begin{tabular}{|c|c|c|c|}
\hline$\% 11.80$ & 28 & ودوردها في المجتمع التربوية العمل عنى ثقافة الحوكمة وبمبادئها وتوضيح أهميتها & 1 \\
\hline$\% 10.50$ & 25 & تدني تفعيل القو انين و التشريعات بما يضمن تطبيق مبادئ الحوكمة. & 2 \\
\hline$\% 10.50$ & 24 & غياب مبادئ الحوكمة كاطار معلن في الخطط الاستر اتيجية للوزارة. & 3 \\
\hline$\% 9$ & 21 & ضعف الاستفادة من خبر ات الدول و المؤسسات المطبقة لمبادئ الحوكمة. & 4 \\
\hline$\% 8.47$ & 20 & تطبيقها الحوركة في إيجاد دليل و اضح للحوكمة و مبادئها وتعزيز منطلبات & 5 \\
\hline$\% 8.00$ & 19 & تمكنها من تطبية صلاحيات الإدارة العليا في قطاع تتمية الموارد البشرية التي & 6 \\
\hline$\% 7.60$ & 18 & البشرية فموض مدى إسهام تطبيق مبادئ الحوكمة في تعزيز تتمية الموارد & 7 \\
\hline$\% 7.60$ & 18 & بالبر امج التأهيلية اءلات وقو انين المساءلة المتبعة مع الإداريين و المستهدفين & 8 \\
\hline$\% 7.20$ & 17 & غبالعملية خطوات التأهيلية وآليات تطبيق مبدأ العدالة عن جميع الأطر اف المعنية & 9 \\
\hline$\% 6.70$ & 16 & غموضى التأهيل آلية تطبيق الضتوفين بالبط المتبعة في المسأيلية المساءلة سواء للموظفين القائمين & 10 \\
\hline$\% 6.70$ & 16 & مشاركة المستهدة اتخاذ القرار ات والبر الإجر التأهيلية ضعيفة الخاصة بالخطط التأهيلية حيث. & 11 \\
\hline$\% 5.90$ & 14 & 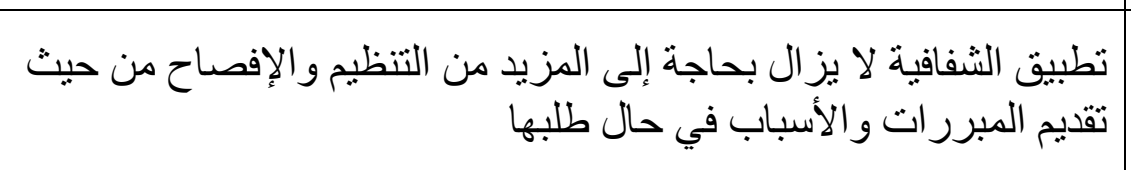 & 12 \\
\hline $99.86 \%$ & 236 & المجموع & \\
\hline
\end{tabular}

يبين الجدول (7) أن عدد الفقرات التي تركزت عليها استجابة عينتي الدراسة بلغت 12 فقرة،

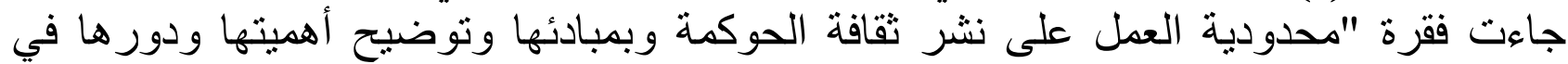

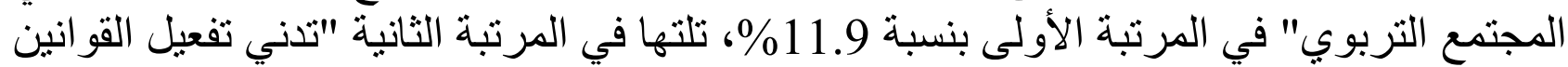

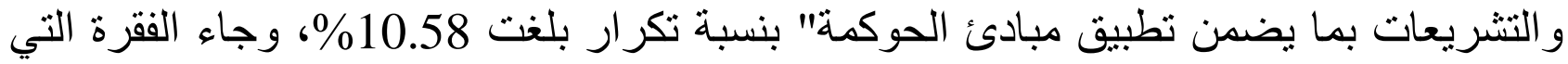

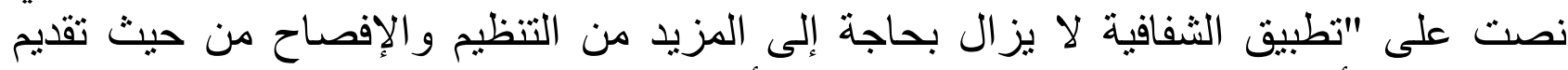
المبرر ات والأسباب في حال طلبها " في المرتبة الأخيرة بنسبة تكرار بلغت لهن (5.90\%).

التحديات التي تواجه تطبيق الحوكمة في قطاع التأهيل من وجهة نظر المستهوفين بالبرامج التأهيلية فيما يلي: تواجه 
أ. غياب الرؤية الو اضحة حول آلية نشر ثقافة الحوكمة بالمجتمع عامةً وبقطاع التأهيل، مثل تتظيم

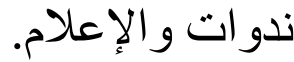

ب. تدني تفعيل القو انين و التشريعات وفق ما وضعت له بما بضمن تطبيق مبادئ الحوكمة. ت. ت ضعف المعرفة بخصائص الحوكمة وفو ائدها، وتدني ثقافة الموظف و المستهدف حول الحوكمة و آلية العمل بها.

ث. هنالك ضعف تتمية تطبيق مبادى الحوكمة لدى العاملين التنمية البشرية فهنالك حاجة ماسة الى نشر ثقافة الحوكمة.

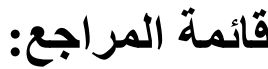

الكسر، شريفة، عوض (2018). دور تطبيق معايير الجودة الثاملة في تحقيق الحكمة الإدارية في الجامعات

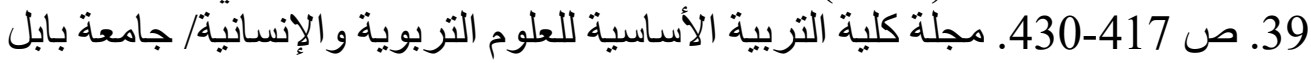
وزارة التربية والتعليم. (2018) خطة الإنماء المهني. المديرية العامة لتنمية الموارد البشرية. سلطنة عمان،

ربابعة، سهى. (2017). "درجة تطبيق الحوكمة الإدارية في جامعة اليرموك من وجهة نظر القادة الأكاديميين

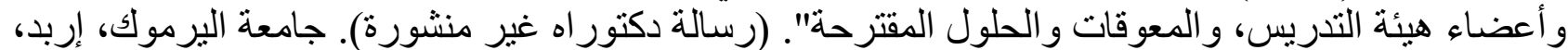
الأردن وزارة التربية و التعليم. (2017). خطة الإنماء المهني. المديرية العامة لتمية الموارد البشرية. سلطنة عمان،

وزارة التربية والتعليم. (2017). تقييم النظام التعليمي لسلطنة عمان الصفوف (12-12). دراسة مشتركة بين وزارة التربية و التعليم واتحاد المنظمات التربوية النيوزيلندية سلطنة عمان، مسقط. المخينية، زكية. (2016). "متطلبات تطبيق مبادئ الحوكمة في مؤسسات التعليم العالي الحكومية بسلطنة

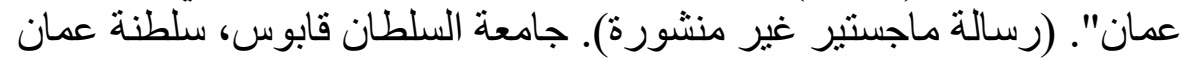
عبويني، ححم؛ والعمري، أحمد. (2016)."تأثير الحاكية المؤسسية و الرافعة المالية على قيمة الثركات

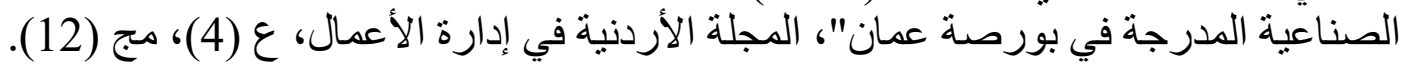
وزارة التربية و التعليم. (2016). خطة الإنماء المهني. المديرية العامة لتنمية الموارد البشرية. سلطنة عمان، مسقط. السنيدي، عائشة. (2014). "دور الحاكمية الرشيدة في تفعيل وظائف الجامعة الرئيسية في الجامعات العمانية: المعيقات وسبل التطوير". (رسالة ماجسنير غير منشورة). جامعة اليرموك، الفئ اربد، الأردن. الاضم، مسيم ، اثر تطبيق قو اعد الحوكمة على جودة الأرباح، 2014، جامعة الثرق الأوسط، رسالة ماجستير.

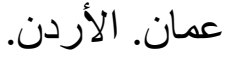
كلبونة، أحمد. (2016). "أثر القواعد الإرشادية لحوكمة الشركات على جودة المعلومات المحاسبية في الثركات الصناعية المساهمة العامة الأردنية". در اسات العلوم الإدارية، 34 (2) (2). 
وزارة التربية و التعليم. (2016). خطة الإنماء المهني. المديرية العامة لتنمية الموارد البشرية. سلطنة عمان، مسقط وزة

اليافعي، شريفة. (2015). "تطوير آليات المشاركة المجتمعية في صنع السياسة التعليمية في ضوء هئه مبادئ

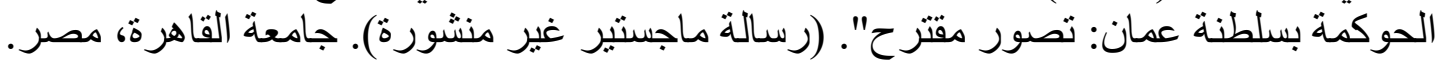
وزارة التربية والتعليم. (2015). خطة الإنماء المهني. المديرية العامة لتنمية الموارد البشرية. سلطنة عمان، مسقط. وزارة التربية و التعليم. (2016). خطة الإنماء المهني. المديرية العامة لتنمية الموارد البشرية. سلطنة عمان، مسقط.

العمرو، حمزة. (2014). "أثر الحوافز المادية والمعنوية في تعزيز عناصر الحوكمة في المؤسسة العامة للضمان الاجتماعي الأردنية: دراسة ميدانية". (رسالة ماجستير غير منشورة). جامعة مؤنة، الكرلية فئ الأردن. المناصير، عمر. (2013). "أثر تطبيق قو اعد حوكمة الثركات على أداء شركات الخدمات المساهمة العامة الأردنية". (رسالة ماجستير غير منشورة). الجامعة الهاشمية، الزرقاءهاء، الأردن. الثويخ، فاروق. (2013). "حالة الحوكمة و الإدارة العامة في الدول العربية خيار ات أم تحديات ومتطلبات جديدة". المنظمة العربية للتنمية الإدارية، المؤتمر السنوي التعام الثالث عشر. - عمّان - المملكة الأردنية

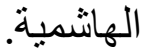

يوسف، طارق. 2013، الثورة هي النتيجة الحتمية لعدم الالتزام بمبادئ الحوكمة.. ورقة عمل مؤتمر الإدارة

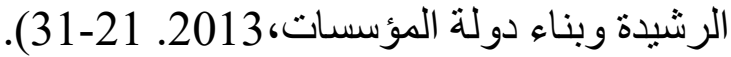
وزارة التربية و التعليم. (2013). خطة الإنماء المهني. المديرية العامة لتنمية الموارد البشرية. سلطنة عمان، مسقط. العازمي، جمال،(2012)، دور حوكمة الثركات في رفع القدرة التنافسية للشركات الكويتية ، جامعة الثرق الأوسط، رسالة ماجستير. عمان. الأردن. وزارة التربية و التعليم. (2012). خطة الإنماء المهني. المديرية العامة لتنمية الموارد البشرية. سلطنة عمان، مسقط. أبو قاعود، أثر أبعاد الحوكمة في عمليات الإصلاح المؤسسي في الإدارة الحكومية: دراسة حالة.. مؤتة للبحوث و الدراسات، سلسلة العلوم الإنسانية والاجتماعية، المجلد السادس والعية العثرون، العدد السابع، 2011 وزارة التربية والتعليم. (2011). خطة الإنماء المهني. المديرية العامة لتمية الموارد البشرية. سلطنة عمان، مسقط. وزارة التربية والتعليم. (2011). خطة الإنماء المهني. المديرية العامة لتنمية الموارد البشرية. سلطنة عمان، مسقط. الثهادات، ححم قاسم. (2008). "أثر تنبي الثركات المساهمة العامة الأردنية لمبادئ الحوكمة على قرارات المستثمر في بورصة عَّمان". (رسالة ماجستير غير منشورة). الجامعة الأردنية، كلية الدر اسات العليا. الأردنة. عبيدات، ذوقان؛ وعبد الحق، كايد؛ و عدس، عبد الرحمن. (2007). البحث العلمي مفهومه و أدواته و أساليبه.

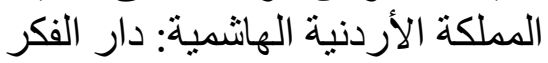

\section{ARABIC REFERENCES IN ROMAN ALPHABET}

Alkisru, Sharifat, Eiwad (2018). Dawr Tatbiq Maeayir Aljawdat Alshshamilat Fi Tahqiq Alhikmat Al'iidariat Fi Aljamieat 39. S 417-430. Majalat Kuliyat Altarbiat Al'asasiat Lileulum Altarbawiat Wal'iinsaniat/ 
Jamieatan Babil

Wizarat Altarbiat Waltaelim. (2018) Khutat Al'iinma' Almahni. Almudiriat Aleamat Litanmiat Almawarid Albashariati. Saltanat Eumaan, Masqat.

Rubabieat, Sahaa. (2017). "Drajat Tatbiq Alhawkamat Al'iidariat Fi Jamieat Alyarmuk Min Wijhat Nazar Alqadat Al'akadimiiyn Wa'aeda' Hayyat Altadris, Walmueawiqat Walhulul Almuqtaraha". (Rsalt Dukturah Ghyr Manshur). Jamieat Alyrmwk, 'lirbid, Al'urdun

Wizarat Altarbiat Waltaelim. (2017). Khutat Al'iinma' Almahni. Almudiriat Aleamat Litanmiat Almawarid Albashariati. Saltanat Eumaan, Masqat.

Wizarat Altarbiat Waltaelim. (2017). Taqyim Alnizam Altaelimii Lisaltanat Euman Alsufuf (1-12). Dirasatan Mushtarakatan Bayn Wizarat Altarbiat Waltaelim Waitihad Almunazamat Altarbawiat Alnayuzilindiat Saltanat Eumaan, Masqat.

Almukhiniatu, Zky. (2016). "Imtatalabat Tatbiq Mabadi Alhukmat Fi Muasasat Altaelim Aleali Alhukumiat Bisiltanat Eman". (Rsalt Majstyr Ghyr Mnshur). Jamieat Alsultan Qabws, Saltanat Eamman.

Eibwini, Muhmada; Waleamri, 'Ahmud. (2016)."Tiathir Alhakimiat Almuasasiat Walraafieat Almaliat Ealaa Qimat Alsharikat Alsinaeiat Almudrajat Fi Bursat Eamaana", Almajalat Al'urduniyat Fi 'lidarat Al'aemali, E (4), Maj (12).

Wizarat Altarbiat Waltaelim. (2016). Khutat Al'iinma' Almahni. Almudiriat Aleamat Litanmiat Almawarid Albashariati. Saltanat Eumaan, Masqat.

Alsanidi, Eayishat. (2014). "Dwr Alhakamiat Alrashidat Fi Tafeil Wazayif Aljamieat Alrayiysiat Fi Aljamieat Aleimaniati: Almueayaqat Wasubul Altatwayra". (Rsalat Majstayr Ghyr Minshurta). Jamieat Alyrmuk, Arbid, Al'urdunn.

Aladmi, Masim , 'lithr Tatbiq Qawaeid Alhawkamat Ealaa Jawdat Al'arbahi, 2014, Jamieat Alshrq Al'awsati, Risalat Majstir. Euman, Al'urdunn.

Kulbunat, 'Ahmud. (2016). "'Athar Alqawaeid Al'iirshadiat Lihawkimat Alsharikat Ealaa Jawdat Almaelumat Almhasbyt Fi Alsharikat Alsinaeiat Almusahamat Aleamat Al'urdaniata". Dirasat Aleulum Al'iidariat, 34 (2).

Wizarat Altarbiat Waltaelim. (2016). Khutat Al'iinma' Almahni. Almudiriat Aleamat Litanmiat Almawarid Albashariati. Saltanat Eumaan, Masqat.

Alyafei, Sharift. (2015). "Tatwir Aliat Almusharakat Almujtamaeiat Fi Sune Alsiyasat Altaelimiat Fi Daw' Mabadi Alhawkamat Bisiltanat Eiman: Tasawur Muqtarah". (Rsalat Majstayr Ghyr Minshurta). Jamieat Alqahirat, Misr.

Wizarat Altarbiat Waltaelim. (2015). Khutat Al'iinma' Almahni. Almudiriat Aleamat Litanmiat Almawarid Albashariati. Saltanat Eumaan, Masqat.

Wizarat Altarbiat Waltaelim. (2016). Khutat Al'iinma' Almahni. Almudiriat Aleamat Litanmiat Almawarid Albashariati. Saltanat Eumaan, Masqat.

Aleamru, Hamzat. (2014). "'Athar Alhawafiz Almadiyat Walmaenawiat Fi Taeziz Eanasir Alhawkamat Fi Almuasasat Aleamat Lildaman Alaijtimaeii Al'urduniati: Dirasat Midanita". (Rsalat Majstayr Ghyr Minshurta). Jamieat Mutata, Alkark, Al'urdunn.

Almanasayr, Eamur. (2013). "Athar Tatbiq Qawaeid Hawkmat Alsharikat Ealaa 'Ada' Sharikat Alkhadamat Almusahamat Aleamat Al'urduniata". (Rsaalat Majstayr Ghyr Minshurta). Aljamieat Alhashmiati, Alzurqa'i, Al'urdunn.

Alshawikh, Faruq. (2013). "Halat Alhawkamat Wal'iidarat Aleamat Fi Alduwal Alearabiat Khiarat 'Am Tahadiyat Wamutatalabat Jadid". Almunazamat Alearabiat Liltanmiat Al'iidariati, Almutamar Alsanawii Aleami Alththalith Eushra. - Emman - Almamlakat Al'urduniyat Alhashmiat.

Yusf, Tariq. 2013, Althawrat Hi Alnatijat Alhatmiat Lieadm Alailtizam Bimabadi Alhawkmat.. Waraqat Eamal Mutamar Al'iidarat Alrashidat Wabina' Dawlat Almuasasat,2013. 21-31).

Wizarat Altarbiat Waltaelim. (2013). Khutat Al'iinma' Almahni. Almudiriat Aleamat Litanmiat Almawarid Albashariati. Saltanat Eumaan, Masqat.

Aleazimi, Jamal,(2012), Dawr Hawkamat Alsharikat Fi Rafe Alqudrat Altanafusiat Lilsharikat Alkuaytiat , Jamieat Alshrq Al'awsati, Risalat Majstir. Euman. Al'urdunn. 
Wizarat Altarbiat Waltaelim. (2012). Khutat Al'iinma' Almahni. Almudiriat Aleamat Litanmiat Almawarid Albashariati. Saltanat Eumaan, Masqat.

'Abu Qaeud, 'Athar 'Abead. (2011). Alhawkamat Fi Eamaliat Al'iislah Almuasisii Fi Al'iidarat Alhukumiat: Dirasatan Hala.. Mutatan Lilbihawth Waldirasati, Silsilat Aleulum Al'iinsaniat Walaijtimaeiati, Almujalid Alssadis Waleishrun, Aleadad Alsaabieu,

Wizarat Altarbiat Waltaelim. (2011). Khutat Al'iinma' Almahni. Almudiriat Aleamat Litanmiat Almawarid Albashariati. Saltanat Eumaan, Masqat.

Wizarat Altarbiat Waltaelim. (2011). Khutat Al'iinma' Almahni. Almudiriat Aleamat Litanmiat Almawarid Albashariati. Saltanat Eumaan, Masqat.

Alshahadatu, Muhamad Qasim. (2008). "'Athar Tabaniy Alsharikat Almusahamat Aleamat Al'urduniyat Limabadi Alhawkamat Ealaa Qararat Almustathmar Fi Bursat Eeman". (Rsaalat Majstayr Ghyr Minshurta). Aljamieat Al'urduniyati, Kuliyat Aldirasat Aleulya. Al'urdunn.

Eubaydat, Dhuqan; Waeabd Alhiq, Kayd; Waeads, Eabd Alrhmn. (2007). Albahth Aleilmiu Mafhumah Wa'adawatih Wa'asalibah. Almamlakat Al'urduniyat Alhashmyt: Dar Alfikr.

\section{REFERENCES}

Abor, Joshua \& K. D. Adjasi, Charles, (2007), "Corporate Governance and the small and medium enterprises sector: theory and implications" Corporate Governance, ISSN. VOI (7), No (2), PP111-122

Lamine mandiang, réflexions autour du concept de gouvernance, Communication présentée dans projet «consolider et élargir la communication citoyenne pour une gouvernance démocratique au Sénégal », Dakar,CESTI : 06-09 mai 2008, p:3, cite web

World Bank, World Bank, 2003, Reforming Public Institutions and Strengthening Governance: A World Bank Strategy Implementation Update Washington: The Public Sector Group , Poverty Reduction and Economic Management (PREM) Net Work.

Johnson, Johnson, Adrianne L.; DuVivier, Roxanne S.; Hambright, W. Grant. 2017. Shared University Governance: Faculty Perceptions on Involvement and Leadership. Leadership and Research in Education, v4 n1 p10-26 201

Lamine mandiang, réflexions autour du concept de gouvernance, Communication présentée dans projet "consolider et élargir la communication citoyenne pour une gouvernance démocratique au Sénégal », Dakar,CESTI : 06-09 mai 2008, p:3, cite web

Etejere, Patricia Agnes Ovigueraye; Aburime, Aminat Ozohu; Aliyu, Olumayowa Kabir; Jekayinfa, Oyeyemi Jumo Towards Quality Governance and Management of West African Universities: The Way Forward. eJEP: e-Journal of Education Policy, Spr 2017

United Nation Development Program, 1997, Governance for Sustainable Human Development, AUNDP Policy Document, New York, January 